\title{
Analysis of clinical significance and prospective molecular mechanism of main elements of the JAK/STAT pathway in hepatocellular carcinoma
}

\author{
XIANGKUN WANG ${ }^{1}$, XIWEN LIAO $^{1}$, TINGDONG YU ${ }^{1}$, YIZHEN GONG $^{2}$, LINBO ZHANG $^{3}$, \\ JIANLU HUANG ${ }^{4}$, CHENGKUN YANG $^{1}$, CHUANGYE HAN $^{1}$, LONG YU ${ }^{1,5}$, GUANGZHI ZHU ${ }^{1}$, \\ WEI QIN ${ }^{1}$, ZHENGQIAN LIU $^{1}$, XIN ZHOU ${ }^{1}$, JUNQI LIU ${ }^{1}$, QUANFA HAN ${ }^{1}$ and TAO PENG ${ }^{1}$ \\ Departments of ${ }^{1}$ Hepatobiliary Surgery, ${ }^{2}$ Colorectal and Anal Surgery, ${ }^{3}$ Health Management and \\ Division of Physical Examination, The First Affiliated Hospital of Guangxi Medical University, Nanning, \\ Guangxi Zhuang Autonomous Region 530021; ${ }^{4}$ Department of Hepatobiliary Surgery, Third Affiliated Hospital of \\ Guangxi Medical University, Nanning, Guangxi Zhuang Autonomous Region 530031; 5 Department of Hepatobiliary and \\ Pancreatic Surgery, The First Affiliated Hospital of Zhengzhou University, Zhengzhou, Henan 450000, P.R. China
}

Received March 9, 2019; Accepted July 17, 2019

DOI: $10.3892 /$ ijo.2019.4862

\begin{abstract}
Hepatocellular carcinoma (HCC) is one the most common malignancies and has poor prognosis in patients. The aim of the present study is to explore the clinical significance of the main genes involved in the Janus kinase (JAK)-signal transducer and activator of transcription (STAT) pathway in HCC. GSE14520, a training cohort containing 212 hepatitis B virus-infected HCC patients from the Gene Expression Omnibus database, and data from The Cancer Genome Atlas as a validation cohort containing $370 \mathrm{HCC}$ patients, were used to analyze the diagnostic and prognostic significance for HCC. Joint-effect analyses were performed to determine diagnostic and prognostic significance. Nomograms and risk score models were constructed to predict HCC prognosis using the two cohorts. Additionally, molecular mechanism analysis was
\end{abstract}

Correspondence to: Professor Tao Peng, Department of Hepatobiliary Surgery, The First Affiliated Hospital of Guangxi Medical University, Nanning, Guangxi Zhuang Autonomous Region 530021, P.R. China

E-mail: pengtaogmu@163.com

Abbreviations: HCC, hepatocellular carcinoma; JAK, Janus kinase; STAT, signal transducer and activator of transcription; HBV, hepatitis B virus; TCGA, The Cancer Genome Atlas; BCLC, Barcelona Clinic Liver Cancer; KEGG, Kyoto Encyclopedia of Genes and Genomes; GSEA, gene set enrichment analysis; BP, biological process; CC, cellular component; MF, molecular function; GO, gene ontology; OS, overall survival; MST, median survival time; CI, confidence interval; HR, hazard ratio; ROC, receiver operating characteristic; PPI, protein-protein interaction

Key words: hepatocellular carcinoma, genome-wide analysis, molecular mechanism, clinical significance, signalling pathway, JAK2, STAT6, Believe performed for the two cohorts. Prognosis-associated genes in the two cohorts were further validated for differential expression using reverse transcription-quantitative polymerase chain reaction of 21 pairs of hepatitis B virus-infected HCC samples. JAK2, TYK2, STAT3, STAT4 and STAT5B had diagnostic significance in the two cohorts (all area under curves $>0.5$; $\mathrm{P} \leq 0.05)$. In addition, JAK2, STAT5A, STAT6 exhibited prognostic significance in both cohorts (all adjusted $\mathrm{P} \leq 0.05$ ). Furthermore, joint-effect analysis had advantages over using one gene alone. Molecular mechanism analyses confirmed that STAT6 was enriched in pathways and terms associated with the cell cycle, cell division and lipid metabolism. Nomograms and risk score models had advantages for HCC prognosis prediction. When validated in 21 pairs of HCC and non-tumor tissue, STAT6 was differentially expressed, whereas JAK2 was not differentially expressed. In conclusion, JAK2, STAT5A and STAT6 may be potential prognostic biomarkers for HCC. JAK2, TYK2, STAT3, STAT4 and STAT5B may be potential diagnostic biomarkers for HCC. STAT6 has a role in HCC that may be mediated via effects on the cell cycle, cell division and lipid metabolism.

\section{Introduction}

Liver cancer is considered the sixth most prevalent tumor type worldwide (1). Hepatocellular carcinoma (HCC) accounts for nearly all (70-85\%) primary liver cancers (2). Many factors, including hepatitis $\mathrm{B}$ or $\mathrm{C}$ virus (HBV) infection, type 2 diabetes, alcohol intake and metabolic syndrome are risk factors for the development of HCC (3). Presently, therapeutic remedies for HCC treatment tend to rely on the Barcelona Clinic Liver Cancer (BCLC) staging system (4), and include surgical resection, locoregional and systemic approaches (2). Surgical approaches consist of liver resection and transplantation for early stage HCC and the application of these procedures is dependent on the cirrhosis, tumor extension and co-morbidities in patients (2). Locoregional 
therapies used in intermediate-stage HCC consist of surgery, ablation and different types of transcatheter arterial chemoembolization $(5,6)$. Even with these treatments, patients still have an unsatisfactory prognosis, with a 5-year survival rate $<10 \%$, which makes liver cancer the second leading cause of cancer-related death worldwide (7). In addition, tumor recurrence was observed in $\sim 70 \%$ of the cases within the first 5 years after tumor resection (5).

HCC is phenotypically and genetically heterogeneous (2). Other than the many important mutations in the telomerase promoter $(8,9)$, tumor suppressor gene TP53 (10), Catenin $\beta-1$, AT-rich interaction domain 1 and axin 1, HCC pathogenesis is often characterized disruption in a series of signaling networks (2). The Janus kinase (JAK)-signal transducer and activator of transcription (STAT) signaling pathway is activated by over 40 cytokines and growth factors, and is associated with cell proliferation, differentiation and apoptosis $(11,12)$. In the signaling pathway, cytokines induce phosphorylation of JAK1-3 and tyrosine kinase 2 (TYK2), followed by the activation of STAT1-6 $(11,12)$. Furthermore, nuclear localization of STATs causes the activation of target genes among three families of inhibitory proteins: Protein inhibitors of activated STATs, the SH2-containg phosphatases and suppressors of cytokine signaling (13-15). JAK1 was also previously identified as a novel therapeutic target in patients with inflammatory HCC in the gp130 mutant population (16). Meanwhile, B7-H3 was reported to promote aggression and invasion of HCC by regulating epithelial-mesenchymal transition via JAK2/STAT3/Slug signaling (17). Calvisi et al (18) demonstrated that high expression of STAT3 was a marker of poor prognosis for HCC patients. Additionally, angiotension II induces angiogenic factors production partly via an angiotensin II type 1/JAK2/STAT3/suppressors of cytokine signaling 3 (SOCS3) signaling pathway in MHCC97-H cells (18). He and Karin (19) suggested that STAT6 was involved in HCC and may be a poor predictor for $\mathrm{HCC}$ prognosis. Nuclear localization of STATs can lead to the activation of STAT target genes, such as the SOCS proteins (14). Inactivation of SOCS1 has been identified in many malignancies, including HCC (19).

At the same time, some members of JAK/STAT signaling pathway have been reported to be associated with HCC, while other factors are not. The current study investigated the clinical significance of mRNA expression of JAK/STAT signaling pathway for HCC diagnosis and prognosis.

\section{Materials and methods}

Ethical approval. This study was approved by the Ethical Review Committee of the First Affiliated Hospital of Guangxi Medical University [approval no. 2015 (KY-E-032)]. Informed consent was provided by all HCC patients.

HCC tissue collection and revers transcription-quantitative PCR (RT-qPCR). A total of $21 \mathrm{HCC}$ tissues and non-tumor tissues $(>1 \mathrm{~cm}$ margin from tumor) of patients with HBV infection were collected between the December 2015 and July 2016 (The First Affiliated Hospital of Guangxi Medical University). Inclusion criteria were as follows: All the patients were determined to have HCC via pathological diagnosis.
Exclusion criteria: Patients of age $<20$ and $>70$ years. HCC and non-tumor tissues were cut into pieces and stored in RNAstore Reagent (DP408; Tiangen Biotech Co., Ltd.) at $4^{\circ} \mathrm{C}$ overnight and transferred to $-80^{\circ} \mathrm{C}$ for long-term storage. Total RNA was extracted from above tissues and reversed into cDNA (Takara Bio, Inc.). Primers for GAPDH, JAK2, STAT5A and STAT6 were synthesized by Sangon Biotech Co., Ltd. with the following sequences (5'-3'): GAPDH, forward GTCAGCCGC ATCTTCTTT, reverse CGCCCAATACGACCAAAT; JAK2, forward AGCCTATCGGCATGGAATATCT, reverse TAA CACTGCCATCCCAAGACA; STAT5A, forward GCAGAG TCCGTGACAGAGG, reverse CCACAGGTAGGGACAGAG TCT; STAT6, forward GTTCCGCCACTTGCCAATG, reverse TGGATCTCCCCTACTCGGTG. DEPC-treated water was purchased from Sangon Biotech Co., Ltd. FastStart Universal SYBR Green Master (ROX) was used for RT-qPCR (Roche Diagnostics). The conditions were as follows: $50^{\circ} \mathrm{C}$ for $2 \mathrm{~min}$, $95^{\circ} \mathrm{C}$ for $10 \mathrm{~min}, 95^{\circ} \mathrm{C}$ for $15 \mathrm{sec}, 60^{\circ} \mathrm{C}$ for $1 \mathrm{~min}(40$ cycles), $95^{\circ} \mathrm{C}$ for $15 \mathrm{sec}, 60^{\circ} \mathrm{C}$ for $1 \mathrm{~min}, 95^{\circ} \mathrm{C}$ for $30 \mathrm{sec}, 60^{\circ} \mathrm{C}$ for $15 \mathrm{sec}$. The $2^{-\Delta \Delta \mathrm{Cq}}$ method was used to calculate the relative expression of mRNAs (20).

Data source. Data from a total of 212 HCC patients with HBV infection were accessed from the GSE14520 dataset in the Gene Expression Omnibus database s a training cohort (platform GPL3921;ncbi.nlm.nih.gov/geo/query/acc.cgi?acc=GSE14520; accessed Sept 3rd, 2018) $(22,22)$. Additionally, data from 370 HCC patients were accessed from the Cancer Genome Atlas (TCGA) database as a validation cohort (https://cancergenome. nih.gov/; accessed Sept 3rd, 2018).

Body map and protein expressions. In addition, expressions of genes in JAK/STAT pathway were collected from Gene Expression Profiling Interactive Analysis website (gepia. cancer-pku.cn/index.html; accessed Sept 8th, 2018), while the protein expressions were obtained from the Human Protein Atlas website (proteinatlas.org/; accessed Sept 8th, 2018) (23).

Diagnosis, prognosis and joint-effect analysis. Diagnostic receiver operating characteristic (ROC) curves were constructed by use of mRNA expressions of tumor and non-tumor tissue samples (GraphPad version 7.0; GraphPad Software, Inc.). The mRNA expressions of tumor tissues were categorized into low and high expressions using the median expression level as the cut-off. Meanwhile, the overall survival was calculated using Kaplan-Meier and Cox proportional hazards regression model (SPSS version 16.0; SPSS, Inc.). Prognosis-related clinical factors, including tumor grade, tumor size, $\alpha$-fetoprotein (AFP), cirrhosis, BCLC stage and radical resection, in two cohorts were adjusted for using the multivariate Cox proportional hazards regression model. Prognosis-related genes were combined for joint-effect analysis.

Gene set enrichment analysis (GSEA). Potential mechanisms, including biological processes and metabolic pathways of JAK/STAT pathway genes, were explored using GSEA (gsea2-2.2.4; software.broadinstitute.org/gsea/index.jsp). Datasets c2.cp.kegg.v6.1.symbols.gmt, c5.bp.b6.1.symbols. gmt, c5.cc.v6.1.symbols.gmt and c5.mf.v6.1.symbols.gmt 
A

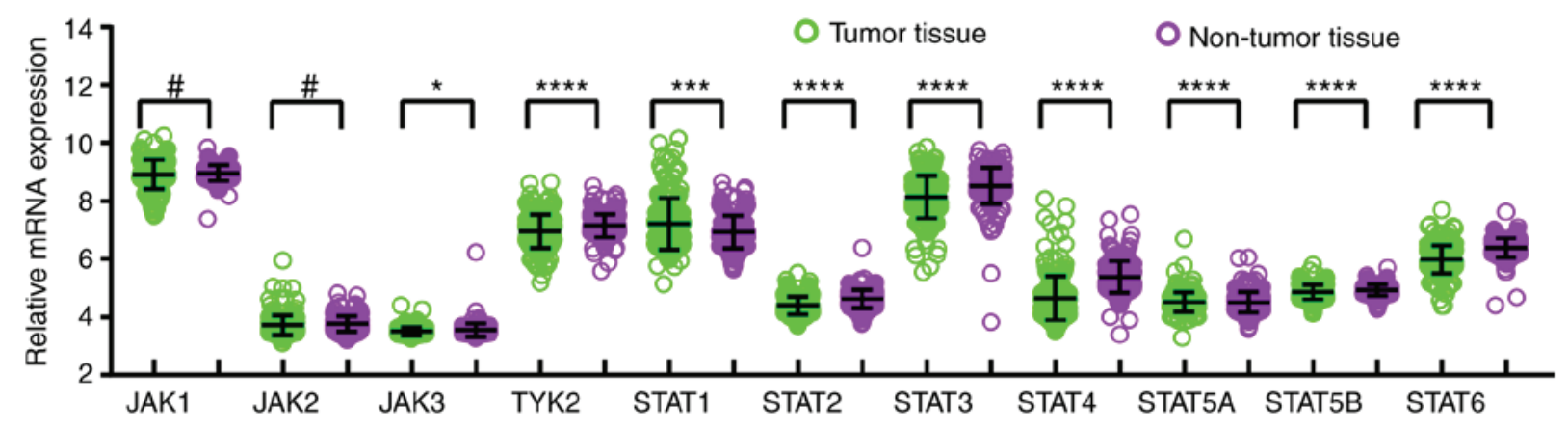

B

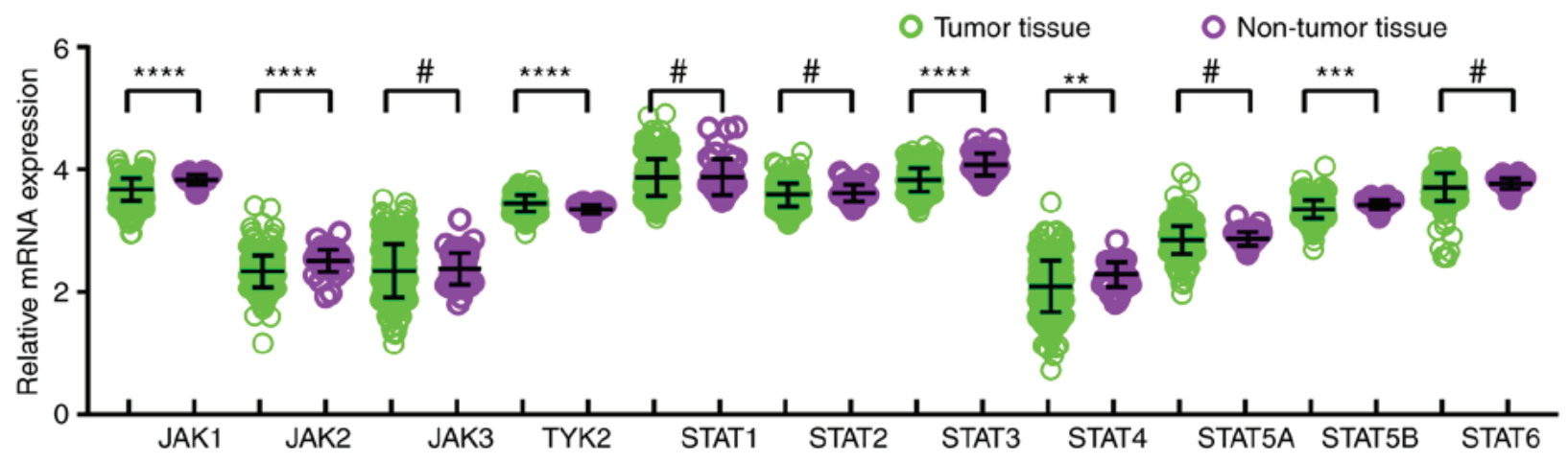

C
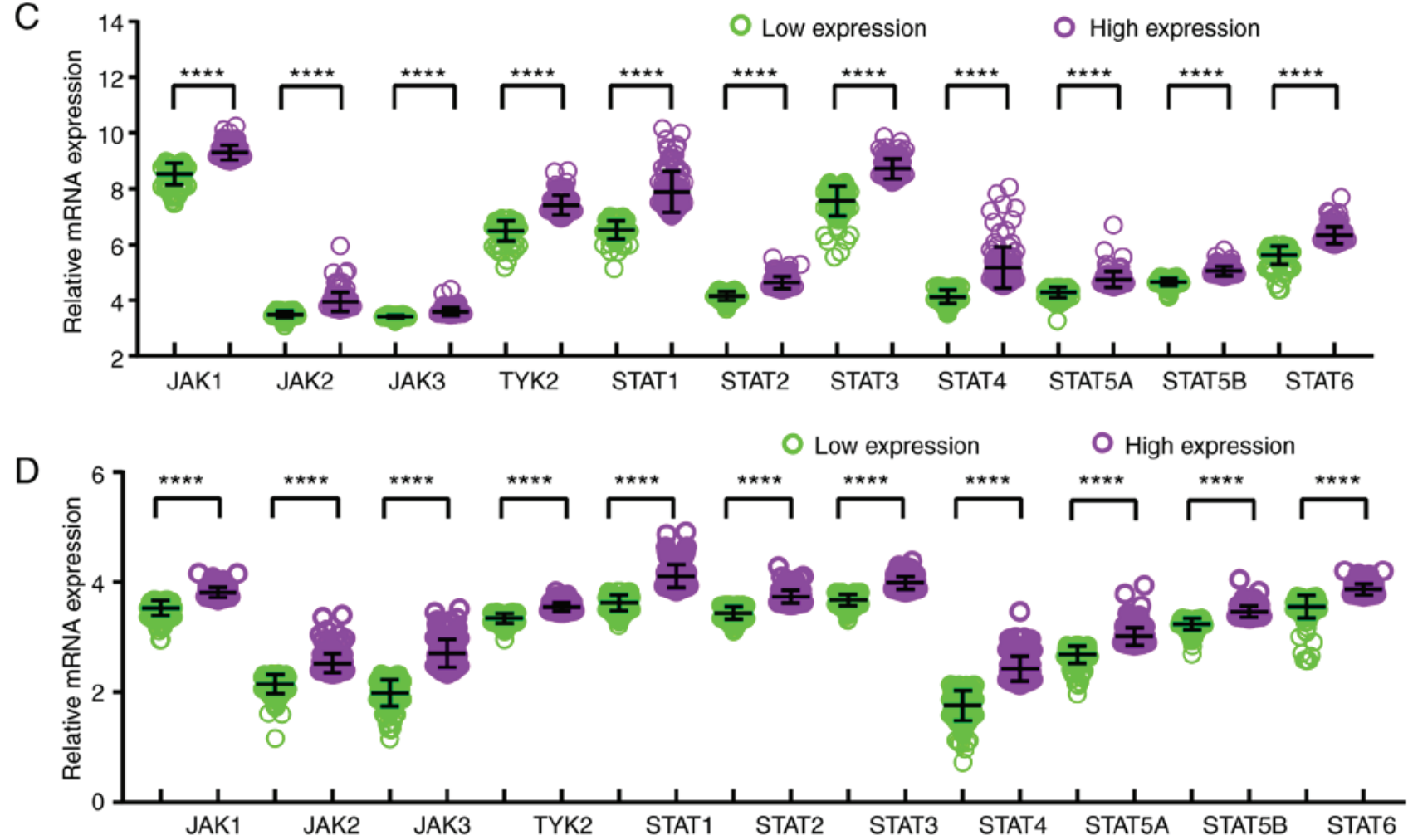

Figure 1. Relative mRNA expressions of key genes of JAK/STAT pathway. Relative mRNA expressions of key genes of JAK/STAT pathway in tumor and non-tumor tissue of the (A) GSE14520 cohort and (B) TCGA cohort. Analysis of low and high expressions of key genes of JAK/STAT pathway in the (C) GSE14520 cohort and (D) TCGA cohort. ${ }^{*} \mathrm{P} \leq 0.05,{ }^{* *} \mathrm{P} \leq 0.01,{ }^{* * *} \mathrm{P} \leq 0.001,{ }^{* * * * *} \mathrm{P} \leq 0.0001,{ }^{*} \mathrm{P}>0.05$. TCGA, The Cancer Genome Atlas; JAK, Janus kinase; TYK2, tyrosine kinase 2; STAT, signal transducer and activator of transcription.

were then analyzed to obtain statistically significant Gene Ontology (GO) terms, including biological process (BP), cellular component (CC) and molecular function (MF), and Kyoto Encyclopedia of Genes and Genomes (KEGG) pathways $(24,25)$.
Risk score model and nomogram construction. For further examination of prognosis-related genes for HCC survival, risk score models were constructed for prognosis prediction. In addition, risk scores, patient survival status, expression heatmap and prognostic ROC curves were constructed in the 

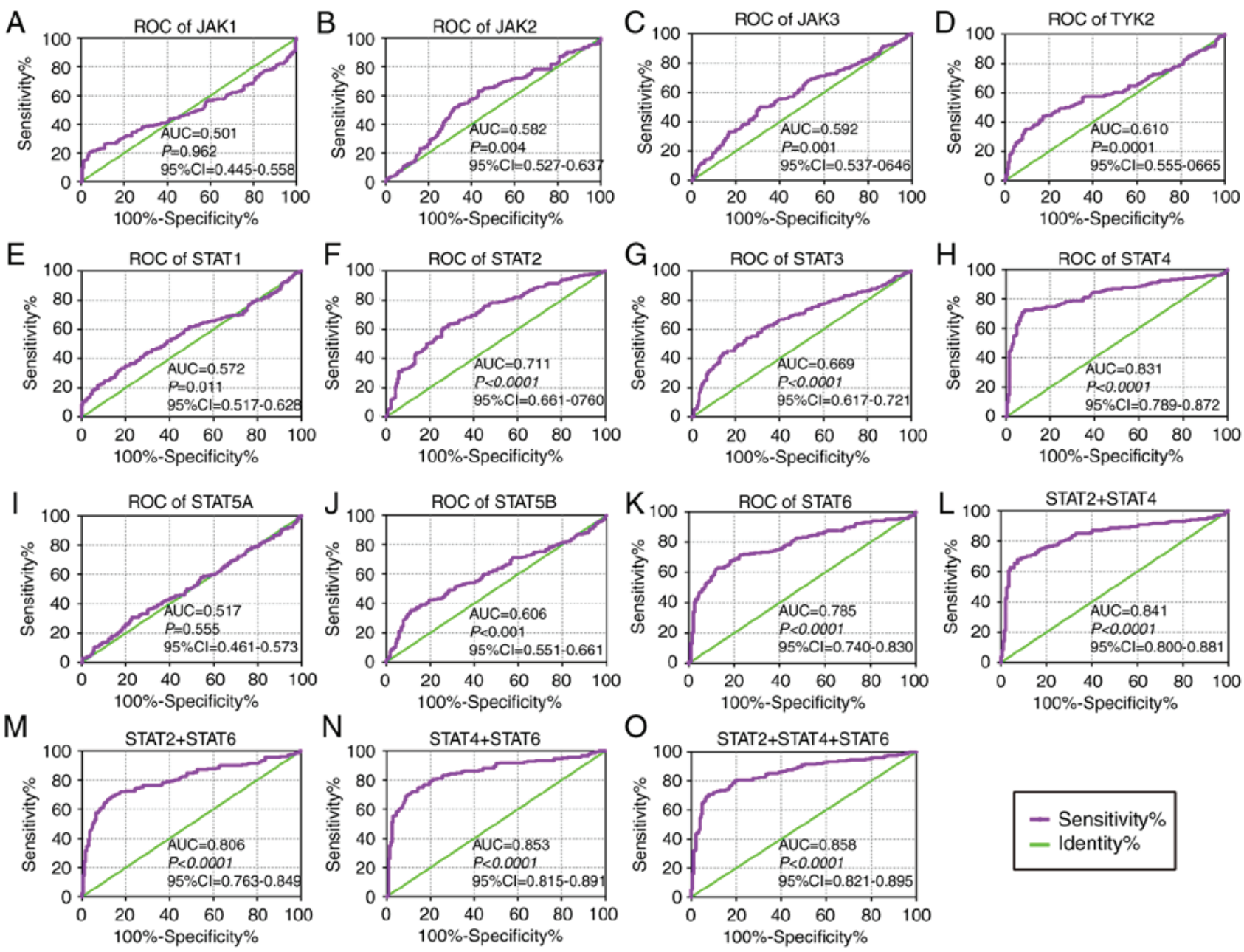

Figure 2. Diagnostic ROC curves of key genes of JAK/STAT pathway using the GSE14520 dataset. ROC curves of JAK/STAT pathway members: (A) JAK1, (B) JAK2, (C) JAK3, (D) TYK2, (E) STAT1, (F) STAT2, (G) STAT3, (H) STAT4, (I) STAT5A, (J) STAT5B and (K) STAT6. ROC curves of combinations: (L) STAT2 + 4, (M) STAT2 + 6, (N) STAT4 + 6 and (O) STAT2 + $4+6$, respectively. ROC, receiver operating characteristic; AUC, area under the curve; CI, confidence interval; JAK, Janus kinase; TYK2, tyrosine kinase 2; STAT, signal transducer and activator of transcription.

model. The formula of the model is as follows: Risk score $=$ expression of gene $\mathrm{e}_{1} \times \beta_{1}$ of gene 1 expression of gene $2 \times \beta_{2}$ of gene $_{2}+\ldots+$ expression of gene $\mathrm{n}_{\mathrm{n}} \times \beta_{\mathrm{n}}$ of gene $\mathrm{g}_{\mathrm{n}}(26-28)$.

Contribution coefficients $(\beta)$ originated from the multivariate Cox proportional hazards regression model. Nomograms were generated using clinical factors and genes for predicting patient survival probability at 1,3 and 5 years.

Interaction analysis. Pearson correlation matrixes among JAK/STAT pathway genes were constructed using R version 3.5.0 (r-project.org/). An interactive gene-gene co-expression network was then constructed using the geneMANIACytoscape plugin (version 3.5.1) and the GO enrichment analysis was visualized using the BiNGO plugin of Cytoscape software version 3.6.0 (29-31). A protein-protein interaction (PPI) network was constructed using STRING (https://string-db.org/cgi/input.pl; accessed Sept 20th, 2018) (32).

Statistical analysis. Kaplan-Meier and box plots were produced using GraphPad software version 7.0 (GraphPad Software, Inc.). Survival analysis was performed by using SPSS software version 16.0 (SPSS, Inc.). The median survival time and Log-rank P-values were calculated using the Kaplan-Meier method; 95\% confidence interval (CI) and hazard ratio (HR) were calculated by univariate and multivariate Cox proportional hazards regression model. $\mathrm{P} \leq 0.05$ was considered to indicate a statistically significant difference.

\section{Results}

Demographic characteristics of GSE14520 and TCGA cohorts. In this study, a total of $212 \mathrm{HBV}$-related HCC patients were enrolled in training cohort, whereas $370 \mathrm{HCC}$ patients were enrolled in the validation cohort. Tumor size, AFP, cirrhosis status and BCLC stage were associated with overall survival (OS; all $\mathrm{P} \leq 0.05$; Table SI) in the GSE14520 cohort. Additionally, HBV infection, tumor stage and radical resection were associated with overall survival (all $\mathrm{P} \leq 0.05$; Table SII) in the TCGA cohort.

$m R N A$, protein and BodyMap expression analysis. In comparison between tumor and normal tissues, JAK3, TYK2, STAT1, STAT2, STAT3, STAT4, STAT5A, STAT5B and STAT6 genes exhibited differentially expressed levels in the GSE14520 cohort (all P $\leq 0.05$; Fig. 1A), and JAK1, JAK2, TYK2, STAT3, STAT4 and STAT5B demonstrated differentially expressed levels in the TCGA cohort (all P $\leq 0.05$; Fig. 1B). Meanwhile, in the 

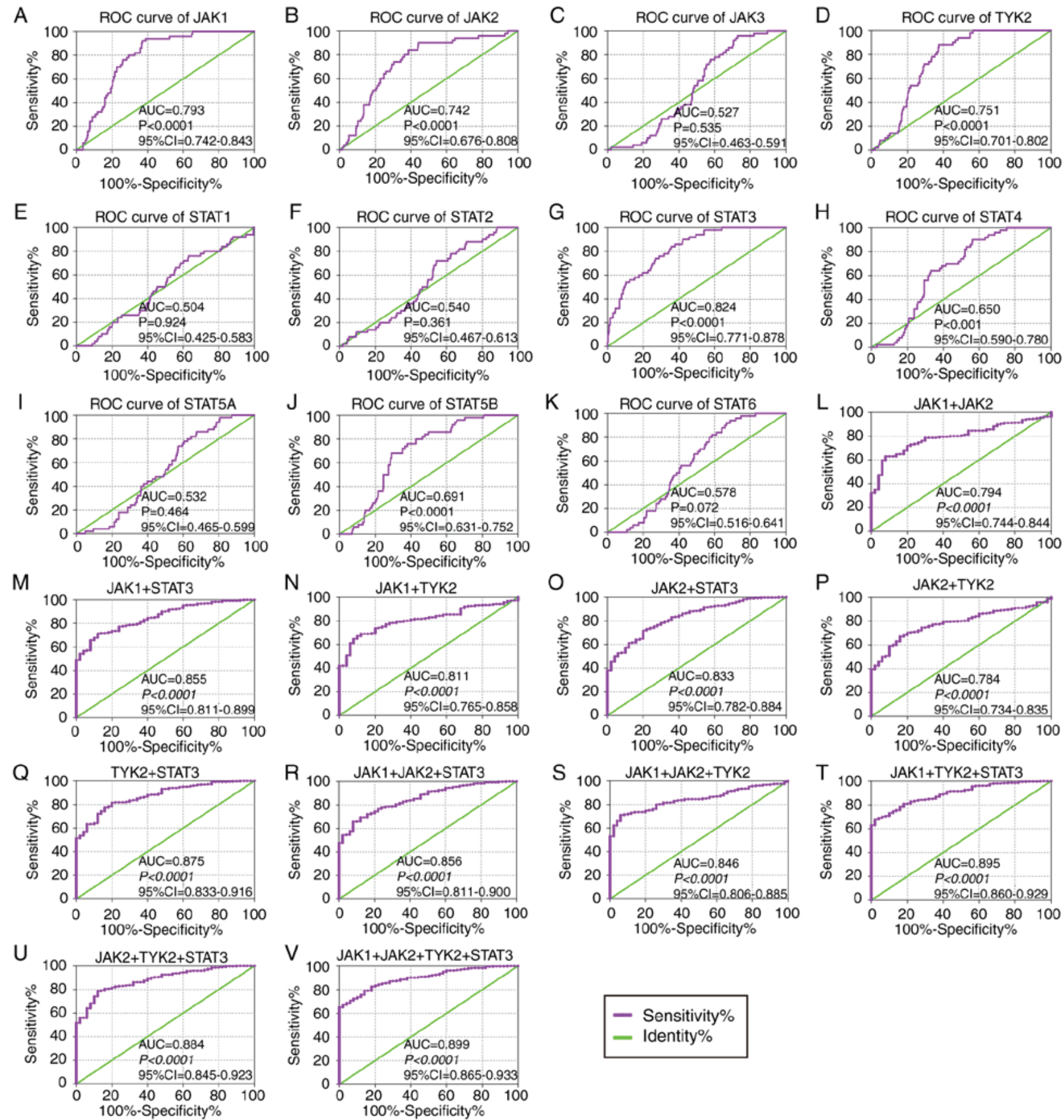

Figure 3. Diagnostic ROC curves of key genes of JAK/STAT pathway using data from The Cancer Genome Atlas. ROC curves of JAK/STAT pathway members: (A) JAK1, (B) JAK2, (C) JAK3, (D) TYK2, (E) STAT1, (F) STAT2, (G) STAT3, (H) STAT4, (I) STAT5A, (J) STAT5B and (K) STAT6. ROC curves of combination of (L) JAK1 + 2, (M) JAK1 + STAT3, (N) JAK1 + TYK2, (O) JAK2 + STAT3, (P) JAK2 + TYK2, (Q) STAT3 + TYK2, (R) JAK1 + 2 + STAT3, (S) JAK1 + 2 + TYK2, (T) JAK1 + STAT3 + TYK2, (U) JAK2 + STAT3 + TYK2 and (V) JAK1 + 2 + STAT3 + TYK2. ROC, receiver operating characteristic; AUC, area under the curve; CI, confidence interval; JAK, Janus kinase; TYK2, tyrosine kinase 2; STAT, signal transducer and activator of transcription.

comparison between low and high expression groups, all the genes showed differently expressed levels in both GSE14520 and TCGA cohorts (all P $\leq 0.05$; Fig. 1C and D). BodyMap expression of JAK/STAT pathway genes in tumor and normal tissues is illustrated in Fig. S1. Protein expression data from the Human Protein Atlas confirmed that STAT3 is the highest expressed of the JAK/STAT pathway proteins in HCC (Fig. S2).

Diagnosis and prognosis analysis. In the diagnostic analysis of the GSE14520 cohort (Fig. 2), JAK2, JAK3, TYK2, STAT1,
STAT2, STAT3, STAT4, STAT5B and STAT6 genes all indicated diagnostic significance for HCC [Fig. 2B-H, J-K; $\mathrm{P} \leq 0.05$; area under curve (AUC) $>0.5$ ]. Others did not show any diagnostic significance (Fig. 2A and I). Of them, STAT2, STAT4 and STAT6 genes showed higher diagnostic ability (AUC >0.7). Their combination also illustrated a higher diagnosis ability compared with using just one gene (Fig. 2L-O). In the diagnostic analysis of TCGA cohort (Fig. 3), JAK1, JAK2, TYK2, STAT3, STAT4 and STAT5B indicated diagnostic significance for HCC (Fig. 3A, B, D, G, H and J; 
A
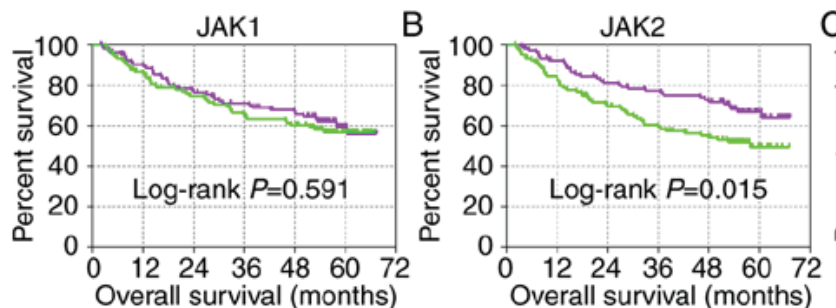

E
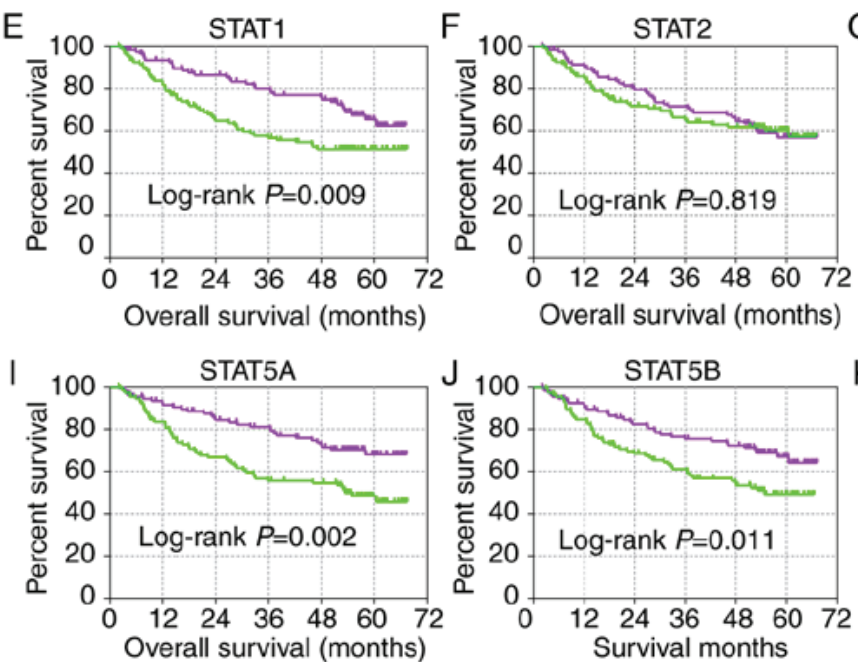
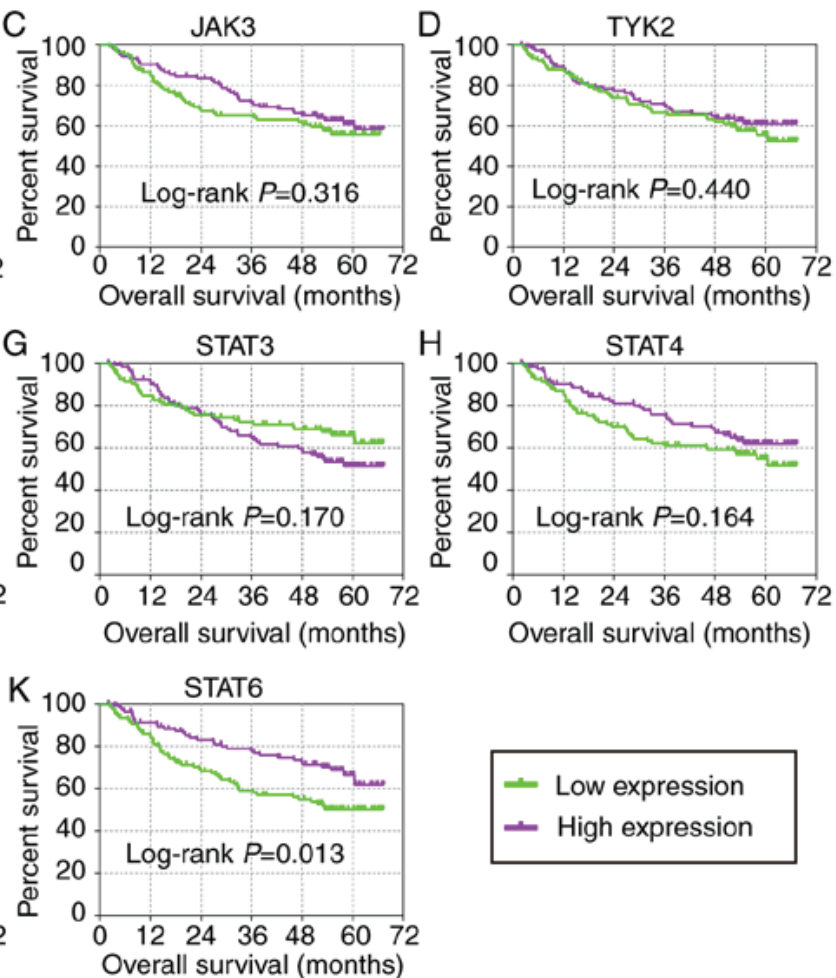

Figure 4. Kaplan-Meier plots of key genes of JAK/STAT pathway in the GSE14520 cohort. (A) JAK1, (B) JAK2, (C) JAK3, (D) TYK2, (E) STAT1, (F) STAT2, (G) STAT3, (H) STAT4, (I) STAT5A, (J) STAT5B and (K) STAT6. JAK, Janus kinase; TYK2, tyrosine kinase 2; STAT, signal transducer and activator of transcription.

$\mathrm{P} \leq 0.05$; AUC $>0.5)$. Others did not show any diagnostic significance (Fig. 3C, E, F, I and K). Of them all, JAK1, JAK2, TYK2 and STAT3 displayed higher diagnosis ability (AUC >0.7). A combination of all genes demonstrated higher diagnosis abilities as compared with just one gene (Fig. 3L-V). In the prognosis analysis of the GSE14520 cohort (Fig. 4), univariate analysis indicated that JAK2, STAT1, STAT5A, STAT5B and STAT6 were associated with OS (all adjusted $\mathrm{P} \leq 0.05$; Table I; Fig. 4B, E and I-K). Others did not show any prognostic significance (Fig. 4A, C, D and F-H). Meanwhile, JAK2, STAT1, STAT3, STAT5A and STAT6 expressions were associated with OS after adjustment for tumor size, cirrhosis, AFP and BCLC stage (all adjusted $\mathrm{P} \leq 0.05$; Table I). In the prognosis analysis of TCGA cohort, univariate analysis showed that STAT4, STAT5A, STAT5B and STAT6 were all associated with OS (all adjusted $\mathrm{P} \leq 0.05$; Table II; Fig. 5H-K). Others did not show any prognostic significance (Fig. 5A-G). Meanwhile, JAK1, JAK2, STAT5A, STAT5B and STAT6 expressions were associated with OS after adjustment for radical resection, tumor stage and HBV infection (all adjusted $\mathrm{P} \leq 0.05$; Table II).

Joint-effect analysis. JAK2, STAT5A and STAT6 demonstrated prognostic significance in both GSE14520 and TCGA cohorts (Tables I and II) and were additionally used in for joint-effect analysis. In the multivariate analysis, prognostic significance was observed among all the groups in the GSE14520 and TCGA cohorts (all adjusted P $\leq 0.05$; Tables III and IV). Groups 1,I, A, i, $\mathbf{\square}, \boldsymbol{\bullet} \bullet$ and $\boldsymbol{\Lambda}$, with most of the poor prognosis indicators, indicated the worst prognosis. However, groups 3, III, C, iiii, $\mathbf{m m}$,

$\star \star \star, \bullet \bullet \bullet$ and $\boldsymbol{\Delta} \mathbf{\Delta} \mathbf{\Delta} \boldsymbol{\Delta}$ showed the best prognosis (Fig. 6).
These results are in line with the fact that combination analysis has advantage over any gene alone.

GSEA results. STAT6 was further explored in analysis of GO terms and KEGG pathways (Figs. 7 and 8). Enriched STAT6 GO terms in both the GSE14520 and TCGA cohorts were enriched 'cell cycle checkpoint', 'cell cycle G1 S phase transition', 'regulation of cell division', 'meiotic cell cycle' and 'cell division' (Figs. 7A-L and 8A-L). Enriched KEGG pathways of STAT6 using the GSE14520 dataset included 'cell cycle', 'nucleotide excision repair', 'DNA replication' and 'homologous recombination', among others (Fig. 7M-P). Meanwhile, enriched KEGG pathways of STAT6 from The Cancer Genome Atlas data included 'drug metabolism cytochrome P450', 'PPAR signaling pathway', 'fatty acid metabolism' and 'metabolism of xenobiotics by cytochrome P450' (Fig. 8M-P).

Construction of nomogram and risk score model. Clinical factors, JAK2, STAT5A and STAT6 were analyzed using nomogram for the GSE14520 (Fig. 3A) and TCGA (Fig. 3B) cohorts. High expressions often cause low points in the two cohorts. The same points indicated highest probability of survival at 1 year and the lowest probability of survival at 5 years. Survival probability at 3 years was in the middle.

In addition, risk score models were constructed for prognosis prediction as presented in Figs. 9A and 10A. Meanwhile, coefficient $\beta$ in the model was obtained from Cox proportional hazards regression model (Table V). The risk score model included risk score ranking, living status, gene expression heat maps and survival plot. The prognostic ROC curves and survival plots indicated that risk score models have values 
Table I. Prognostic analysis of genes in JAK/STAT signaling pathway for overall survival in GSE14520 dataset.

\begin{tabular}{|c|c|c|c|c|c|c|c|}
\hline \multirow[b]{2}{*}{ Gene } & \multirow{2}{*}{$\begin{array}{l}\text { No. of } \\
\text { patients } \\
(n=212)\end{array}$} & \multicolumn{6}{|c|}{ Overall survival } \\
\hline & & $\begin{array}{l}\text { No. of } \\
\text { events }\end{array}$ & $\begin{array}{c}\text { MST } \\
\text { (month) }\end{array}$ & $\mathrm{HR}(95 \% \mathrm{CI})$ & $\begin{array}{c}\text { Crude } \\
\text { P-value }\end{array}$ & HR (95\%CI) & $\begin{array}{l}\text { Adjusted } \\
\text { P-value }\end{array}$ \\
\hline \multicolumn{8}{|l|}{ JAK1 } \\
\hline Low expression & 106 & 43 & NA & Ref. & & Ref. & \\
\hline High expression & 106 & 39 & NA & $0.888(0.576-1.370)$ & 0.591 & $0.913(0.588-1.419)$ & 0.687 \\
\hline \multicolumn{8}{|l|}{ JAK2 } \\
\hline Low expression & 106 & 49 & 57.9 & Ref. & & Ref. & \\
\hline High expression & 106 & 33 & NA & $0.578(0.372-0.900)$ & $0.015^{\mathrm{b}}$ & $0.585(0.370-0.925)$ & $0.022^{\mathrm{b}}$ \\
\hline \multicolumn{8}{|l|}{ JAK3 } \\
\hline Low expression & 106 & 43 & NA & Ref. & & Ref. & \\
\hline High expression & 106 & 39 & NA & $0.801(0.519-1.236)$ & 0.316 & $1.019(0.651-1.595)$ & 0.934 \\
\hline \multicolumn{8}{|l|}{ TYK2 } \\
\hline Low expression & 106 & 44 & NA & Ref. & & Ref. & \\
\hline High expression & 106 & 38 & NA & $0.843(0.546-1.301)$ & 0.440 & $0.831(0.535-1.290)$ & 0.409 \\
\hline \multicolumn{8}{|l|}{ STAT1 } \\
\hline Low expression & 106 & 49 & NA & Ref. & & Ref. & \\
\hline High expression & 106 & 33 & NA & $0.555(0.357-0.863)$ & $0.009^{\mathrm{b}}$ & $0.617(0.394-0.966)$ & $0.035^{\mathrm{b}}$ \\
\hline \multicolumn{8}{|l|}{ STAT2 } \\
\hline Low expression & 106 & 40 & NA & Ref. & & Ref. & \\
\hline High expression & 106 & 42 & NA & $0.951(0.616-1.467)$ & 0.819 & $1.184(0.749-1.873)$ & 0.469 \\
\hline \multicolumn{8}{|l|}{ STAT3 } \\
\hline Low expression & 106 & 34 & NA & Ref. & & Ref. & \\
\hline High expression & 106 & 48 & NA & $1.360(0.877-2.111)$ & 0.170 & $1.650(1.065-2.576)$ & $0.028^{\mathrm{b}}$ \\
\hline \multicolumn{8}{|l|}{ STAT4 } \\
\hline Low expression & 106 & 46 & NA & Ref. & & Ref. & \\
\hline High expression & 106 & 36 & NA & $0.734(0.474-1.135)$ & 0.164 & $0.683(0.440-1.060)$ & 0.089 \\
\hline \multicolumn{8}{|l|}{ STAT5A } \\
\hline Low expression & 106 & 52 & 53.3 & Ref. & & Ref. & \\
\hline High expression & 106 & 30 & NA & $0.487(0.311-0.764)$ & $0.002^{\mathrm{b}}$ & $0.498(0.313-0.791)$ & $0.003^{\mathrm{b}}$ \\
\hline \multicolumn{8}{|l|}{ STAT5B } \\
\hline Low expression & 106 & 49 & 54.8 & Ref. & & Ref. & \\
\hline High expression & 106 & 33 & NA & $0.563(0.361-0.876)$ & $0.011^{\mathrm{b}}$ & $0.696(0.441-1.098)$ & 0.119 \\
\hline \multicolumn{8}{|l|}{ STAT6 } \\
\hline Low expression & 106 & 50 & NA & Ref. & & Ref. & \\
\hline High expression & 106 & 32 & NA & $0.569(0.365-0.887)$ & $0.013^{\mathrm{b}}$ & $0.529(0.337-0.831)$ & $0.006^{\mathrm{b}}$ \\
\hline
\end{tabular}

for prognosis in the GSE14520 (Fig. 9B and C) and TCGA (Fig. 10B and C) cohorts.

Co-expression interactions, PPI network and enrichment analysis. Pearson correlation matrices of JAK/STAT pathway genes were constructed to show the correlations among them (Fig. 11A and B). Additionally, co-expression interaction and pathways along with PPI networks demonstrated complex interactions at the gene and protein levels (Fig. 11C and D).
Enrichment analysis identified BP, CC and MF GO terms associated with JAK/STAT pathway (Fig. S4). A schematic of the JAK/STAT pathway is presented in Fig. S5. In particular, the mechanisms of these genes involved in JAK/STAT signaling pathway were consistent with the GSEA results produced in the present study.

Validation of expressions of JAK2, STAT5A and STAT6 using RT-qPCR. A total of 21 pairs of HBV-infected HCC 
Table II. Prognostic analysis of genes in JAK/STAT signaling pathway for overall survival in The Cancer Genome Atlas database.

\begin{tabular}{|c|c|c|c|c|c|c|c|}
\hline \multirow[b]{2}{*}{ Gene } & \multirow[b]{2}{*}{$\begin{array}{l}\text { Patients } \\
(n=370)\end{array}$} & \multicolumn{6}{|c|}{ Overall survival } \\
\hline & & $\begin{array}{l}\text { No. of } \\
\text { event }\end{array}$ & $\begin{array}{l}\text { MST } \\
\text { (days) }\end{array}$ & $\mathrm{HR}(95 \% \mathrm{CI})$ & $\begin{array}{l}\text { Crude } \\
\text { P-value }\end{array}$ & $\mathrm{HR}(95 \% \mathrm{CI})$ & $\begin{array}{l}\text { Adjusted } \\
\text { P-value }\end{array}$ \\
\hline \multicolumn{8}{|l|}{ JAK1 } \\
\hline Low expression & 185 & 70 & 1,685 & Ref. & & Ref. & \\
\hline High expression & 185 & 60 & 2,116 & $0.790(0.557-1.119)$ & 0.184 & $0.542(0.364-0.807)$ & $0.003^{\mathrm{b}}$ \\
\hline \multicolumn{8}{|l|}{ JAK2 } \\
\hline Low expression & 185 & 69 & 1,622 & Ref. & & Ref. & \\
\hline High expression & 185 & 61 & 2,116 & $0.781(0.552-1.105)$ & 0.163 & $0.574(0.388-0.848)$ & $0.005^{\mathrm{b}}$ \\
\hline \multicolumn{8}{|l|}{ JAK3 } \\
\hline Low expression & 185 & 69 & 1,622 & Ref. & & Ref. & \\
\hline High expression & 185 & 61 & 1,694 & $0.859(0.609-1.213)$ & 0.389 & $0.816(0.551-1.208)$ & 0.310 \\
\hline \multicolumn{8}{|l|}{ TYK2 } \\
\hline Low expression & 185 & 69 & 1,490 & Ref. & & Ref. & \\
\hline High expression & 185 & 61 & 2,456 & $0.824(0.583-1.165)$ & 0.274 & $0.799(0.541-1.180)$ & 0.260 \\
\hline \multicolumn{8}{|l|}{ STAT1 } \\
\hline Low expression & 185 & 69 & 1,694 & Ref. & & Ref. & \\
\hline High expression & 185 & 61 & 1,685 & $0.874(0.618-1.237)$ & 0.448 & $0.909(0.609-1.358)$ & 0.641 \\
\hline \multicolumn{8}{|l|}{ STAT2 } \\
\hline Low expression & 185 & 70 & 1,423 & Ref. & & Ref. & \\
\hline High expression & 185 & 60 & 2,486 & $0.744(0.526-1.053)$ & 0.095 & $0.715(0.481-1.063)$ & 0.098 \\
\hline \multicolumn{8}{|l|}{ STAT3 } \\
\hline Low expression & 185 & 68 & 1,622 & Ref. & & Ref. & \\
\hline High expression & 185 & 62 & 2,116 & $0.851(0.602-1.203)$ & 0.360 & $0.727(0.495-1.069)$ & 0.105 \\
\hline \multicolumn{8}{|l|}{ STAT4 } \\
\hline Low expression & 185 & 73 & 1,423 & Ref. & & Ref. & \\
\hline High expression & 185 & 57 & 2,486 & $0.693(0.490-0.981)$ & $0.038^{\mathrm{b}}$ & $0.730(0.487-1.095)$ & 0.128 \\
\hline \multicolumn{8}{|l|}{ STAT5A } \\
\hline Low expression & 185 & 72 & 1,147 & Ref. & & Ref. & \\
\hline High expression & 185 & 58 & 2,456 & $0.626(0.442-0.888)$ & $0.009^{\mathrm{b}}$ & $0.648(0.435-0.967)$ & $0.033^{\mathrm{b}}$ \\
\hline \multicolumn{8}{|l|}{ STAT5B } \\
\hline Low expression & 185 & 78 & 1,271 & Ref. & & Ref. & \\
\hline High expression & 185 & 52 & 2,456 & $0.594(0.418-0.845)$ & $0.004^{\mathrm{b}}$ & $0.604(0.408-0.895)$ & $0.012^{\mathrm{b}}$ \\
\hline \multicolumn{8}{|l|}{ STAT6 } \\
\hline Low expression & 185 & 75 & 1,372 & Ref. & & Ref. & \\
\hline High expression & 185 & 55 & 2,456 & $0.594(0.418-0.843)$ & $0.004^{\mathrm{b}}$ & $0.531(0.357-0.790)$ & $0.002^{\mathrm{b}}$ \\
\hline
\end{tabular}

tissue used to validate the mRNA expression levels of JAK2, STAT5A and STAT6 in tumor and non-tumor tissues. Due to the low sample size available for validation, it is clear that not all results were consistent with the data from the GSE14520 HBV infected-HCC cohort (Fig. S6). STAT6 was differentially expressed between tumor and non-tumor tissues $(\mathrm{P}=0.013)$, whereas JAK2 was not $(\mathrm{P}=0.245)$, which is in line with the GSE14520 cohort. For STAT5A, the results were not in accordance with the GSE14520 cohort, as it was not differentially expressed between tumor and non-tumor tissues in the 21 tissue pairs $(\mathrm{P}=0.08)$; however, this is in line with the result of the TCGA cohort.

\section{Discussion}

In the present study, the diagnostic and prognostic clinical significance of the JAK/STAT signaling pathway in HCC was investigated using GSE14520, HBV-infected cohort and 
Table III. Joint-effect analysis of prognosis-related genes for overall survival in the GSE14520 cohort.

\begin{tabular}{|c|c|c|c|c|c|c|c|}
\hline \multirow[b]{2}{*}{ Group } & \multicolumn{3}{|c|}{ Expression } & \multicolumn{4}{|c|}{ Overall survival } \\
\hline & JAK2 & STAT5A & STAT6 & Events/total & MST (months) & Adjusted HR (95\% CI) & Adjusted P-value \\
\hline 1 & Low & Low & & $34 / 61$ & 32.6 & Ref. & $0.002^{\mathrm{b}}$ \\
\hline 2 & $\begin{array}{l}\text { Low } \\
\text { High }\end{array}$ & $\begin{array}{l}\text { High } \\
\text { Low }\end{array}$ & & $33 / 90$ & NA & $0.572(0.340-0.961)$ & $0.035^{\mathrm{b}}$ \\
\hline 3 & High & High & & $15 / 61$ & NA & $0.339(0.181-0.638)$ & $0.001^{\mathrm{b}}$ \\
\hline I & Low & & Low & $31 / 56$ & 32.6 & Ref. & $<0.001^{\mathrm{b}}$ \\
\hline II & $\begin{array}{l}\text { Low } \\
\text { High }\end{array}$ & & $\begin{array}{l}\text { High } \\
\text { Low }\end{array}$ & $37 / 100$ & NA & $0.443(0.269-0.728)$ & $0.001^{\mathrm{b}}$ \\
\hline III & High & & High & $14 / 56$ & NA & $0.326(0.171-0.619)$ & $0.001^{\mathrm{b}}$ \\
\hline $\mathrm{A}$ & & Low & Low & $33 / 61$ & 33.0 & Ref. & $0.001^{\mathrm{b}}$ \\
\hline $\mathrm{B}$ & & $\begin{array}{l}\text { Low } \\
\text { High }\end{array}$ & $\begin{array}{l}\text { High } \\
\text { Low }\end{array}$ & $36 / 90$ & NA & $0.569(0.350-0.927)$ & $0.023^{\mathrm{b}}$ \\
\hline $\mathrm{C}$ & & High & High & $13 / 61$ & NA & $0.287(0.149-0.544)$ & $<0.001^{\mathrm{b}}$ \\
\hline $\mathrm{i}$ & Low & Low & Low & $21 / 34$ & 28.2 & Ref. & $<0.0001^{\mathrm{b}}$ \\
\hline ii & $\begin{array}{l}\text { Low } \\
\text { Low } \\
\text { High }\end{array}$ & $\begin{array}{l}\text { Low } \\
\text { High } \\
\text { Low }\end{array}$ & $\begin{array}{l}\text { High } \\
\text { Low } \\
\text { Low }\end{array}$ & $35 / 76$ & NA & $0.485(0.277-0.851)$ & $0.012^{\mathrm{b}}$ \\
\hline iii & $\begin{array}{l}\text { Low } \\
\text { High } \\
\text { High }\end{array}$ & $\begin{array}{l}\text { High } \\
\text { Low } \\
\text { High }\end{array}$ & $\begin{array}{l}\text { High } \\
\text { High } \\
\text { Low }\end{array}$ & $18 / 64$ & NA & $0.263(0.135-0.513)$ & $<0.0001^{\mathrm{b}}$ \\
\hline iiii & High & High & High & $8 / 38$ & NA & $0.208(0.090-0.478)$ & $<0.001^{\mathrm{b}}$ \\
\hline
\end{tabular}

${ }^{a}$ P-values were adjusted for tumor size, cirrhosis, $\alpha$-fetoprotein and Barcelona Clinic Liver Cancer stage; ${ }^{b}$ significant P-values and $95 \%$ CI. JAK2, Janus kinase 2; STAT, signal transducer and activator of transcription; NA, not available; MST, median survival time; HR, hazard ratio; 95\% CI, 95\% confidence interval; Ref., reference.
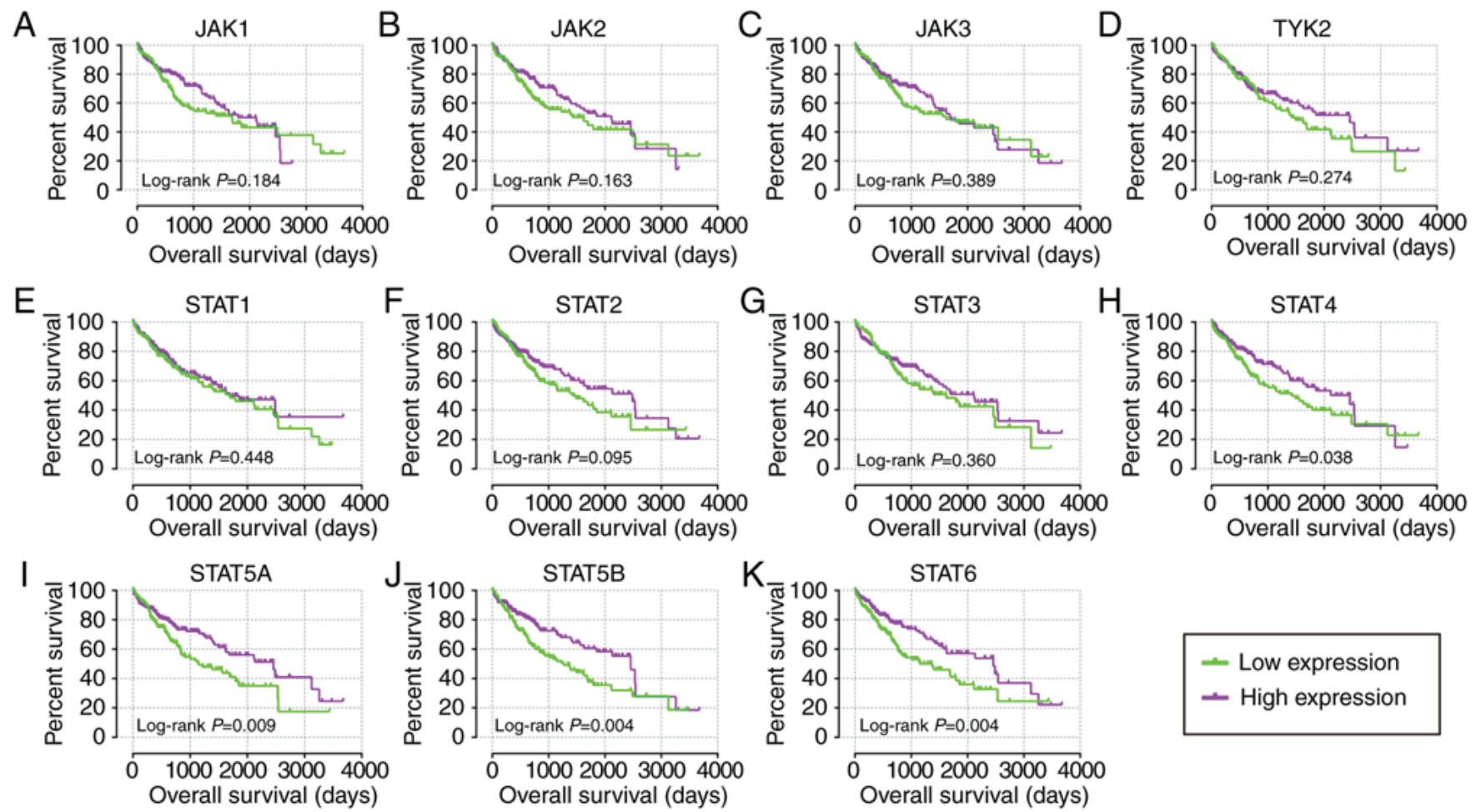

Figure 5. Kaplan-Meier plots of key genes of JAK/STAT pathway in The Cancer Genome Atlas cohort. (A) JAK1, (B) JAK2, (C) JAK3, (D) TYK2, (E) STAT1, (F) STAT2, (G) STAT3, (H) STAT4, (I) STAT5A, (J) STAT5B and (K) STAT6. JAK, Janus kinase; TYK2, tyrosine kinase 2; STAT, signal transducer and activator of transcription. 
Table IV. Joint-effect analysis of prognosis-related genes for overall survival in The Cancer Genome Atlas cohort.

\begin{tabular}{|c|c|c|c|c|c|c|c|}
\hline \multirow[b]{2}{*}{ Group } & \multicolumn{3}{|c|}{ Expression } & \multicolumn{4}{|c|}{ Overall survival } \\
\hline & JAK2 & STAT5A & STAT6 & Events/total & MST (days) & Adjusted HR (95\% CI) & Adjusted P-value ${ }^{a}$ \\
\hline घ & Low & Low & & $39 / 100$ & 1,005 & Ref. & $0.004^{\mathrm{b}}$ \\
\hline \multirow[t]{2}{*}{$\mathbf{\square}$} & Low & High & & $63 / 170$ & 1,423 & $0.703(0.453-1.090)$ & 0.115 \\
\hline & High & Low & & & & & \\
\hline $\mathbf{m}$ & High & High & & $28 / 100$ & 2,456 & $0.390(0.223-0.682)$ & $0.001^{\mathrm{b}}$ \\
\hline$\star$ & Low & & Low & $38 / 91$ & 1,005 & Ref. & $<0.001^{\mathrm{b}}$ \\
\hline \multirow[t]{2}{*}{$\star \star$} & Low & & High & $68 / 188$ & 1,423 & $0.536(0.345-0.834)$ & $0.006^{\mathrm{b}}$ \\
\hline & High & & Low & & & & \\
\hline$\star \star \star \star$ & High & & High & 24/91 & 2,456 & $0.285(0.158-0.515)$ & $<0.0001^{b}$ \\
\hline$\bullet$ & & Low & Low & $45 / 94$ & 802 & Ref. & $0.001^{\mathrm{b}}$ \\
\hline \multirow[t]{2}{*}{$\bullet \bullet$} & & Low & High & $57 / 182$ & 1,685 & $0.542(0.348-0.843)$ & $0.007^{\mathrm{b}}$ \\
\hline & & High & Low & & & & \\
\hline$\bullet \bullet \bullet$ & & High & High & $28 / 94$ & 2,486 & $0.402(0.238-0.677)$ & $0.001^{\mathrm{b}}$ \\
\hline $\boldsymbol{\Delta}$ & Low & Low & Low & $24 / 46$ & 768 & Ref. & $<0.001^{\mathrm{b}}$ \\
\hline \multirow[t]{3}{*}{$\Delta \boldsymbol{\Delta}$} & Low & Low & High & $50 / 147$ & 1,852 & $0.516(0.308-0.863)$ & $0.012^{\mathrm{b}}$ \\
\hline & Low & High & Low & & & & \\
\hline & High & Low & Low & & & & \\
\hline \multirow[t]{3}{*}{$\Delta \mathbf{\Delta} \Delta$} & Low & High & High & $44 / 123$ & 1,560 & $0.357(0.204-0.625)$ & $<0.001^{\mathrm{b}}$ \\
\hline & High & Low & High & & & & \\
\hline & High & High & Low & & & & \\
\hline$\Delta \Delta \Delta \Delta$ & High & High & High & $12 / 54$ & 3,258 & $0.208(0.099-0.438)$ & $<0.0001^{b}$ \\
\hline
\end{tabular}

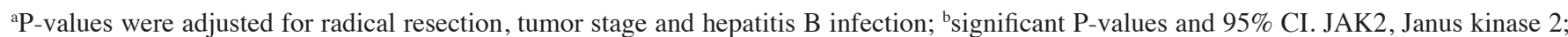
STAT, signal transducer and activator of transcription; MST, median survival time; HR, hazard ratio; 95\% CI, 95\% confidence interval.

TCGA cohorts. JAK2, JAK3, TYK2, STAT1, STAT2, STAT3, STAT4, STAT5B and STAT6 genes had diagnostic significance for HCC in the GSE14520 cohort. Meanwhile, JAK1, JAK2, TYK2, STAT3, STAT4 and STAT5B showed diagnostic significance in the TCGA cohort. This indicates that JAK2, TYK2, STAT3, STAT4 and STAT5B may be diagnostic biomarkers for HCC. JAK2, STAT1, STAT3, STAT5A and STAT6 in the GSE14520 cohort, and JAK1, JAK2, STAT5A, STAT5B and STAT6 in TCGA cohort, were correlated with HCC prognosis, indicating that JAK2, STAT5A and STAT6 may be potential prognostic biomarkers for HCC. The gene combination analyses for both diagnosis and prognosis have advantages over using any one gene alone. Additionally, molecular mechanism exploration using GSEA indicated that STAT6 was enriched in terms associated with the cell cycle and cell division, and the 'fatty acid metabolism', 'drug metabolism cytochrome P450' and 'PPAR signaling pathway' KEGG pathways. Additionally, the nomograms and risk score models were constructed and showed advantage for prediction of HCC prognosis. Furthermore, validation of expression of the prognosis-related genes from the two cohorts (JAK2, STAT5A and STAT6) using tumor and non-tumor tissues samples. STAT6 was differentially expressed between tumor and non-tumor tissues, but JAK2 was not.

The JAK/STAT signaling pathway is a principal signaling transduction pathway stimulated by many crucial cytokines involved in sepsis, including interferon- $\gamma$, and interleukin-4,
$-6,-10$ and $-12(33-38)$. By binding with the corresponding receptor, several cytokines activate JAK kinases, which can selectively phosphorylate STATs (33). Subsequently, the STAT proteins translocate to the nucleus and mediate the transcription of target genes (33). The JAK/STAT signaling pathway consists of the JAK and STAT gene families. The JAK gene family is composed of JAK1, JAK2, JAK3 and TYK2, while the STAT gene family is made up of STAT1, STAT2, STAT3, STAT4, STAT5A, STAT5B and STAT6 (33). Three members of the JAK family, JAK1, JAK2 and JAK3, are expressed universally, whereas TYK2 was found to be mainly expressed in the hematopoietic cells $(39,40)$. The Src-homology 2 (SH2) domain is an $\sim 100$-residue motif that binds to phosphotyrosine residues and provides a mechanism for reading the code (41). Additionally, it has a crucial role in the recruitment of the cytokine receptors and recognition of specific receptor phosphotyrosine motifs. The $\mathrm{SH} 2$ domain is involved in JAK activation and STAT dimerization $(42,43)$.

Complete deficiency of STAT3, STAT5A and STAT5B is a lethal event in mice, which is also consistent with the broad and crucial roles of these proteins (44). Other members, STAT1, STAT2, STAT4, and STAT6, have more restricted functions. They tend to have important roles in host defense and immunoregulation (44). More specifically, STAT3 localizes to mitochondria where it promotes oxidative phosphorylation and membrane permeability (45). This effect is dependent on serine phosphorylation, not tyrosine phosphorylation. STATs 

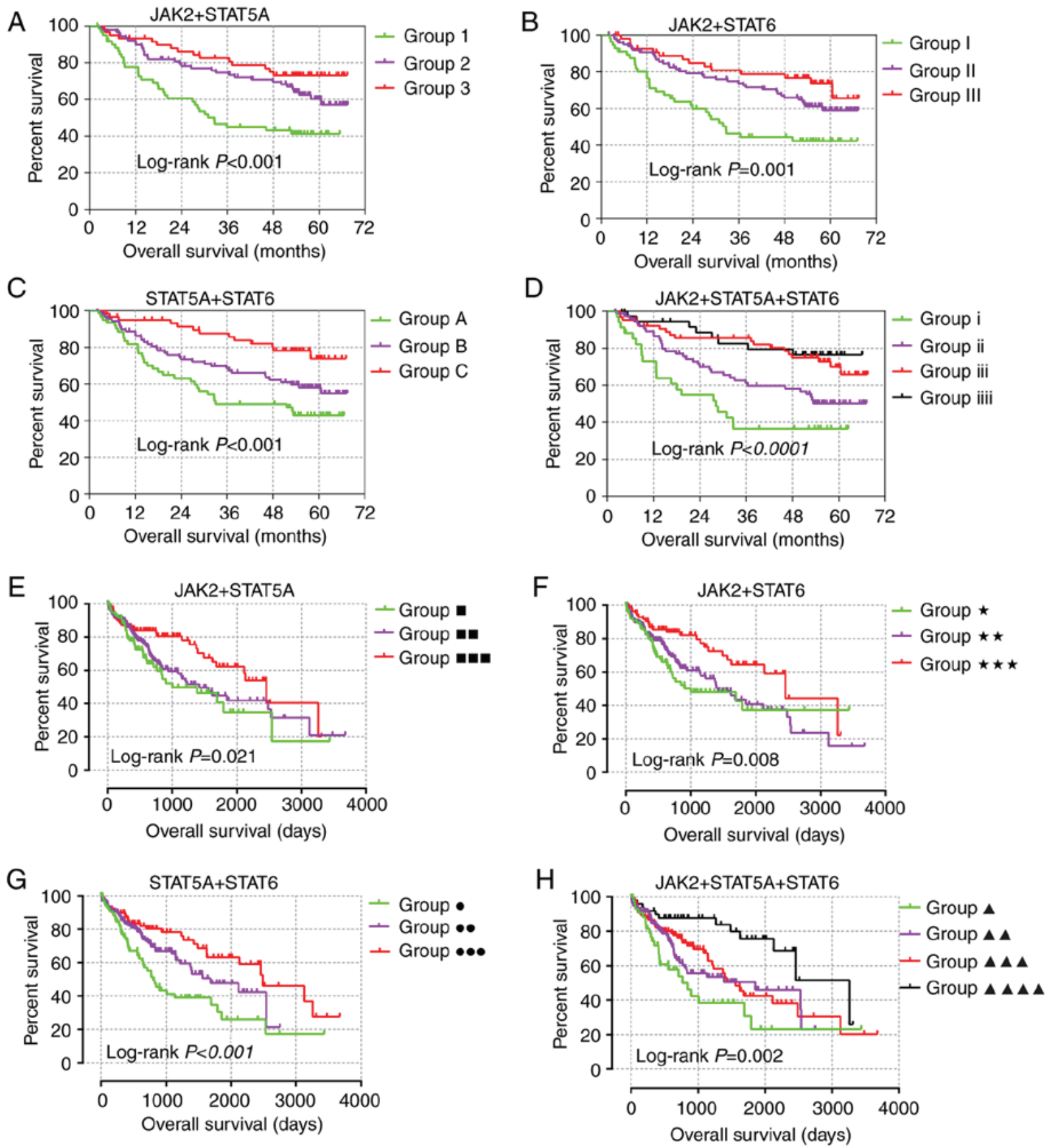

Figure 6. Joint-effect analysis of prognosis-related genes in two cohorts. Joint-effect analysis of (A) JAK2 + STAT5A, (B) JAK2 + STAT6, (C) STAT5A + 6, (D) JAK2 + STAT5A + 6 in the GSE14520 cohort; Joint-effect analysis of (E) JAK2 + STAT5A, (F) JAK2 + STAT6, (G) STAT5A + 6 and (H) JAK2 + STAT5A+ 6 in The Cancer Genome Atlas cohort, respectively.

are considered to be associated with environments where cellular respiration is changed, including cellular stress and cancer (46).

Consecutive activation of JAKs and STATs was discovered and shown to be associated with malignancies in the 1990s (47). STAT hyperactivity, typically including STAT3 and STAT5, is considered to be able to induce cellular transformation downstream of classic oncogenic markers, such as BCR-ABL, Src and Ras. STAT hyperactivity is also recognized as a defining characteristic of most solid and blood malignancies (48). JAK1 mutation was revealed to be associated with the development of acute myeloid leukemia (49). Following knockdown of leukemia inhibitory factor receptor, phosphorylation of JAK1 was increased and promoted HCC metastasis (50). Long non-coding RNA 00152 was reported to activate the JAK2-STAT3 signaling pathway to promote the development of HCC (51). JAK2/STAT3 signaling was reported to be activated by long non-coding RNA HOST2 and linked to epithelial-mesenchymal transition, proliferation, migration and invasion capacity of HCC cells (52). An increased protein level of JAK3 was observed when evaluating the anti-tumor immunostimulatory activity of polysaccharides from Salvia chinensis Benth in mice bearing HCC cells (53). TYK2/STAT3 signaling was previously reported to be associated with poor prognosis of HCC via high expression of claudin-17 (54). STAT1 was reported reduce 

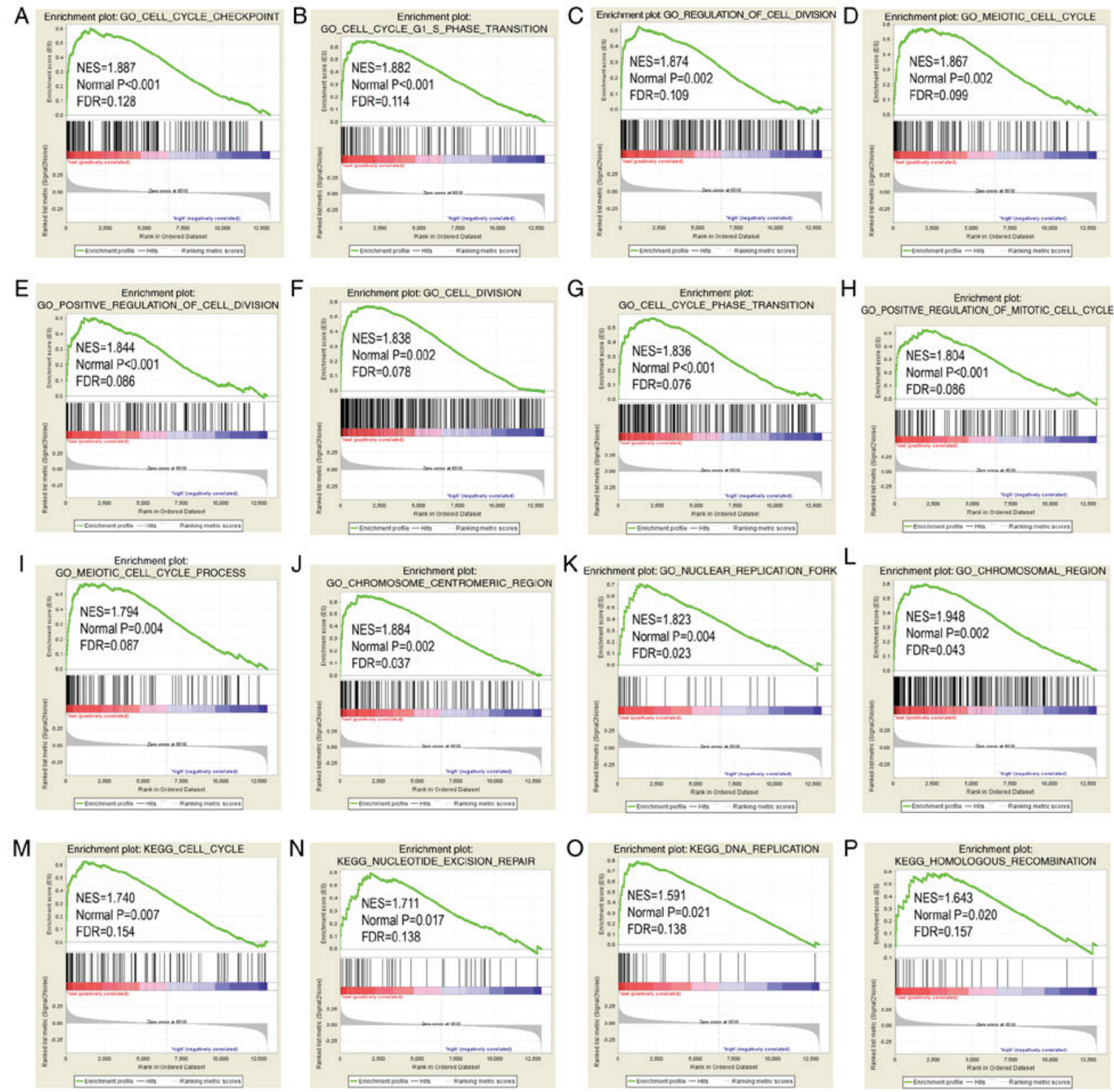

Figure 7. GO and KEGG pathway results of STAT6 in the GSE14520 cohort. (A-L) GO term and (M-P) KEGG pathways in gene set enrichment analysis. STAT6, signal transducer and activator of transcription 6; GO, Gene Ontology; KEGG, Kyoto Encyclopedia of Genes and Genomes.

the growth ability of HepG2 cell by regulating p53-mediated cell cycling and apoptosis (55). STAT1 and STAT2 were demonstrated to decrease the growth capacity of HepG2 cells via increased expression stimulated by phosphatidylethanolamine (56). The rs7574865 polymorphism in STAT4 was found to be a risk factor for HCC in a meta-analysis (57). Additionally, somatic mutation of JAK2 was found to be associated with a number of hematologic tumors $(58,59)$, while gain-of-function JAK2 mutations are involved in myeloproliferative malignancies (60). JAK3 mutations were found to be associated with leukemia and lymphoma (58), and secondary mutations in JAK3 were identified in juvenile myelomonocytic leukemia. Furthermore, JAK3 is considered to be associated with disease progression (61). Mutations in JAK3 and TYK2 have been reported to be associated with primary immunodeficiency, such as severe combined immune deficiency (44). While patients with STAT1 mutations are susceptible to mycobacterial and virus infections, STAT2 mutations predispose patients to virus infection, and individuals with STAT3 mutations are susceptible to fungal infection (44). It is well established that STATs can directly bind to DNA and, thus, function as classical transcription factors (62). This is in line with the GSEA results of the present study that showed that STATs are involved in DNA replication and replication fork.

Next-generation sequencing has led to an explosion of genome-wide association studies (GWAS) in which disease occurrence has been associated with single nucleotide polymorphisms (SNPs) in affected populations (63). As such, GWAS technology has identified SNPs within STAT genes, 
A

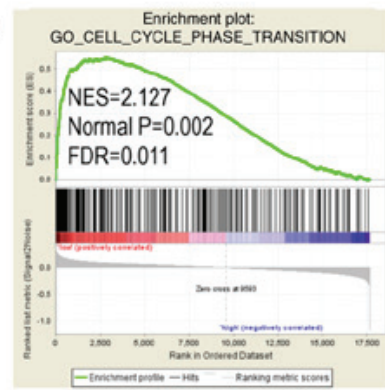

E

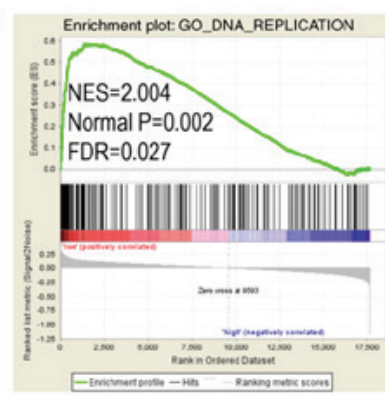

| Enichmentplot GO_MITOTIC_NUCLEAR_DMSION

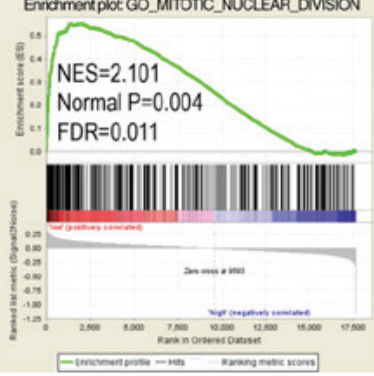

M

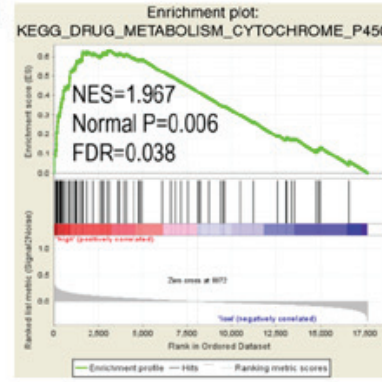

B
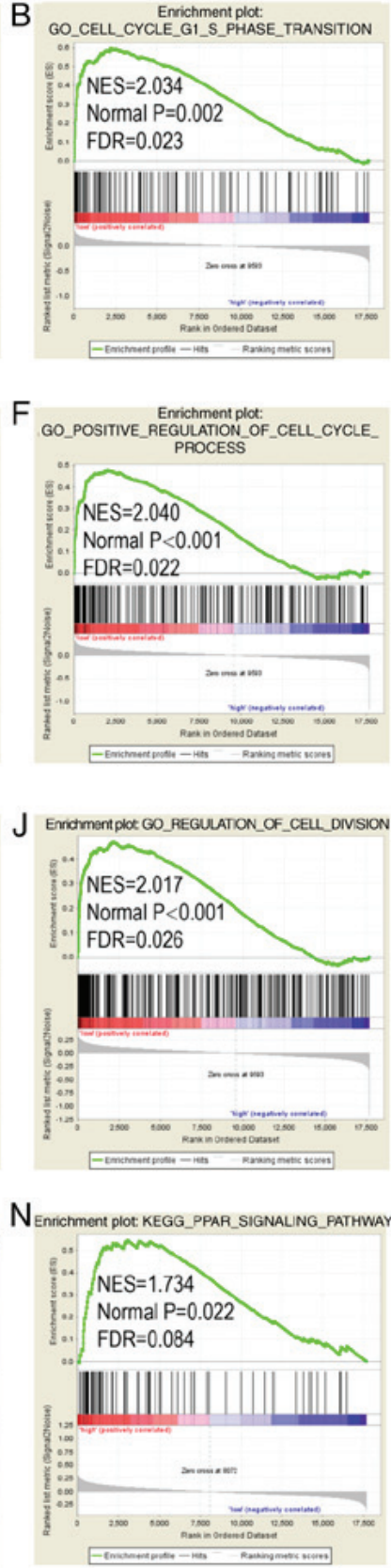
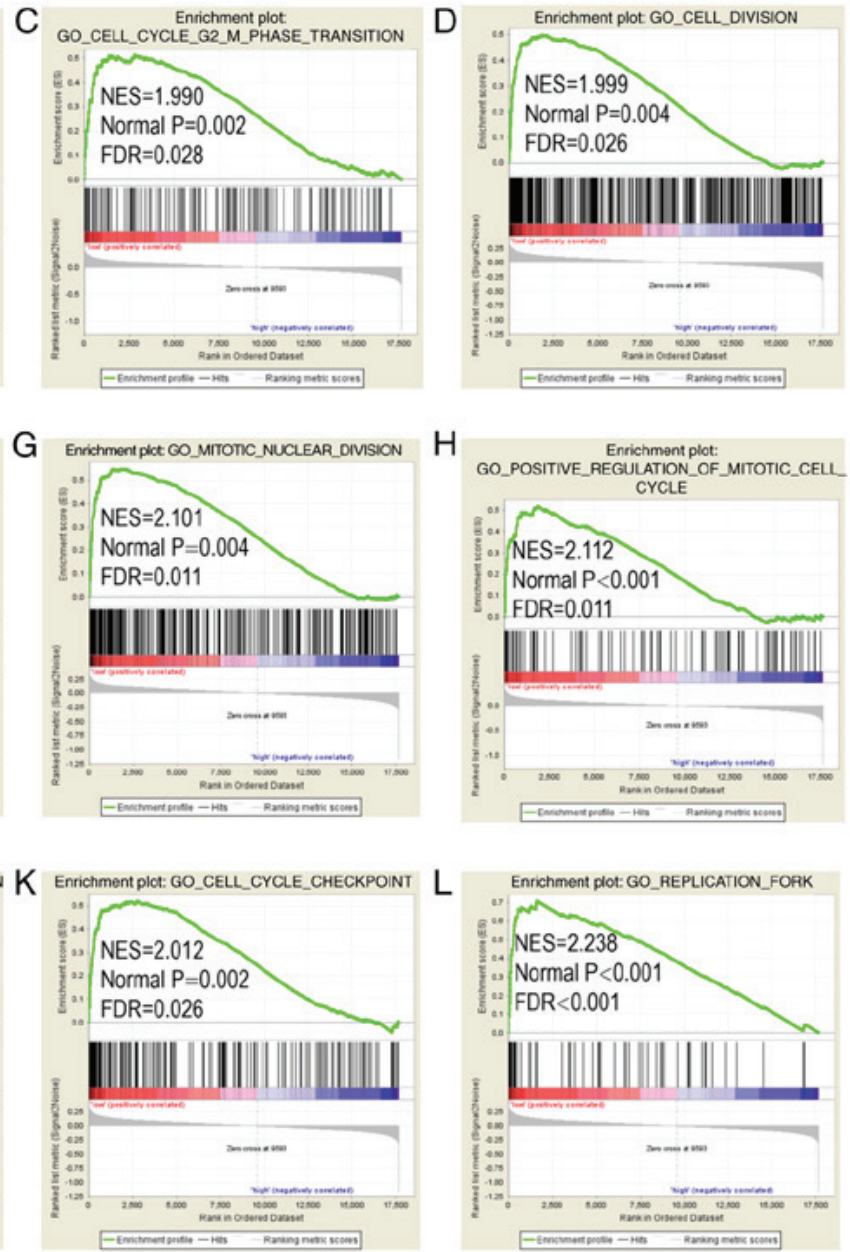

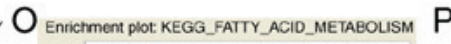
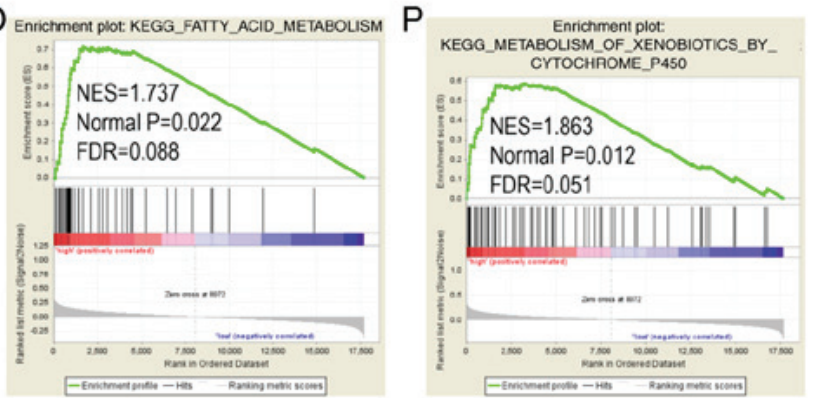

Figure 8. GO and KEGG pathway results of STAT6 in The Cancer Genome Atlas cohort. (A-L) GO term and (M-P) KEGG pathways in gene set enrichment analysis. STAT6, signal transducer and activator of transcription 6; GO, Gene Ontology; KEGG, Kyoto Encyclopedia of Genes and Genomes.

with STAT3 SNPs associated with Crohn's disease, psoriasis and ankylosing spondylitis, STAT4 SNPs associated with rheumatoid arthritis, Crohn's disease, systemic lupus erythematosus and Sjogren's syndrome, and STAT6 SNPs associated with asthma (62). SNPs in STAT3 have been identified to be associated with Crohn's disease, Sjogren's syndrome and systemic lupus erythematosus, while SNPs in STAT6 have been associated with asthma $(64,65)$. JAK2/STAT5A/B signaling tends to promote metastatic progression of prostate cancer by inducing epithelial-mesenchymal transition and stem cell properties (66). Additionally, interleukin 17 stimulates a REG3//JAK2/STAT3 inflammatory pathway seems to promote the transition from chronic pancreatitis to pancreatic cancer (67).

GSEA in the current study explored specific mechanism, demonstrating that STAT6 is involved in the cell cycle, DNA replication and lipid metabolism, which is in agreement with results of KEGG pathway. High expression of STAT3 indicated a poor prognosis for $\mathrm{HCC}$ in multivariate analysis, which is in line with exiting studies (68-70). Existing evidence also indicates that STAT6 is involved in the development of HCC and could serve as a predictor of poor prognosis for patients with HCC (71). In the present study, high expression of STAT6 serves as a predictor of good prognosis. Unlike the results of Shi et al (72) in which JAK2 deficiency in mice had a protective role against HCC, the results of the current study indicated that high expression of JAK2 actually provides protection against HCC. Therefore, further studies are needful to further explore specific mechanisms of JAK2 in cancer. In addition, diagnostic ability analysis was performed to demonstrate that JAK2, TYK2, STAT3, STAT4 and STAT5B may serve as 
Table V. Risk score model construction of genes in GSE14520 dataset and TCGA database.

\begin{tabular}{|c|c|c|c|c|c|}
\hline \multicolumn{6}{|c|}{ A, GSE14520 } \\
\hline Variable & $\beta$ & SE & Wald & HR $(95 \% \mathrm{CI})$ & P-value \\
\hline Tumor size & 0.038 & 0.269 & 0.020 & $1.039(0.613-1.761)$ & 0.886 \\
\hline Cirrhosis & -1.072 & 0.736 & 2.122 & $0.342(0.081-1.448)$ & 0.145 \\
\hline \multicolumn{6}{|l|}{ BCLC stage } \\
\hline 0 & & & 28.571 & & $<0.0001$ \\
\hline A & 1.440 & 0.726 & 3.938 & $4.223(1.018-17.518)$ & 0.047 \\
\hline $\mathrm{B}$ & 1.828 & 0.789 & 5.362 & $6.219(1.324-29.209)$ & 0.021 \\
\hline $\mathrm{C}$ & 2.976 & 0.780 & 14.551 & $19.612(4.25-90.496)$ & 0.0001 \\
\hline AFP & 0.194 & 0.230 & 0.717 & $1.214(0.774-1.904)$ & 0.397 \\
\hline JAK2 & -0.500 & 0.239 & 4.398 & $0.606(0.380-0.968)$ & 0.036 \\
\hline STAT5A & -0.592 & 0.239 & 6.127 & $0.553(0.346-0.884)$ & 0.013 \\
\hline STAT6 & -0.616 & 0.231 & 7.101 & $0.540(0.343-0.850)$ & 0.008 \\
\hline
\end{tabular}

B, TCGA

\begin{tabular}{|c|c|c|c|c|c|}
\hline Variable & $\beta$ & SE & Wald & $\operatorname{HR}(95 \% \mathrm{CI})$ & P-value \\
\hline \multicolumn{6}{|l|}{ Tumor stage } \\
\hline I & & & 8.832 & & 0.012 \\
\hline II & 0.249 & 0.265 & 0.881 & $1.283(0.763-2.159)$ & 0.348 \\
\hline III + IV & 0.669 & 0.227 & 8.673 & $1.952(1.251-3.045)$ & 0.003 \\
\hline Radical resection & 0.266 & 0.360 & 0.548 & $1.305(0.645-2.642)$ & 0.459 \\
\hline HBV infection & -0.854 & 0.266 & 10.305 & $0.426(0.253-0.717)$ & 0.001 \\
\hline JAK2 & -0.567 & 0.200 & 8.045 & $0.567(0.383-0.839)$ & 0.005 \\
\hline STAT5A & -0.320 & 0.206 & 2.405 & $0.726(0.485-1.088)$ & 0.121 \\
\hline STAT6 & -0.631 & 0.205 & 9.507 & $0.532(0.356-0.795)$ & 0.002 \\
\hline
\end{tabular}

TCGA, The Cancer Genome Atlas; SE, standard error; HR, hazard ratio; 95\% CI, 95\% confidence interval; BCLC, Barcelona Clinic Liver Cancer; HBV, hepatitis B virus; JAK2, Janus kinase 2; STAT, signal transducer and activator of transcription.

potential diagnostic biomarkers, which has not been examined previously.

In the validation cohort analyzed via RT-qPCR, three genes, JAK2, STAT5A and STAT6, consistently showed elevated expression in tumor tissues compared with in non-tumor tissues. Nonetheless, these results were not consistent with previous results in the GSE14520 and TCGA cohorts. Racial difference, patient numbers and unknown differences in the clinicopathological characteristics may be the main factors causing this inconsistency.

The present study had some limitations that should be recognized. Firstly, there should be additional datasets used to validate these findings. Additionally, further investigation should use a multi-centre and multi-racial validation cohort to explore clinical significance. Finally, there is a need to designate for functional trials to investigate the mechanisms that JAK2, STAT5A and STAT6 are involved in, including the proliferation, invasion and metastasis ability of HCC.

The present study revealed that genes in JAK/STAT signaling pathway have diagnostic and prognostic clinical significance for HCC. In particular, JAK2, TYK2, STAT3,
STAT4 and STAT5B may be potential diagnostic biomarkers for HCC. Meanwhile, JAK2, STAT5A and STAT6 may be potential prognostic biomarkers for HCC. A combination analysis of multiple genes for diagnosis and prognosis has advantages over any one gene alone. Additionally, molecular mechanism exploration using GSEA indicated that STAT6 was enriched in cell cycle, cell division, fatty acid metabolism, drug metabolism cytochrome P450 and in the PPAR signaling pathway. Nomograms and risk score models were generated for HCC prognosis prediction. STAT6 was differentially expressed between tumor and non-tumor tissues in the validation cohort, which confirmed the result from the GSE14520 cohort. In future studies, well-designed functional trials are required to confirm the mechanisms by which these genes are involved in HCC development, particularly STAT6.

\section{Acknowledgements}

The authors would like to acknowledge researchers for their contribution on open access of GEPIA, STRING and The Human Protein Atlas website and thank Professor Minhao 


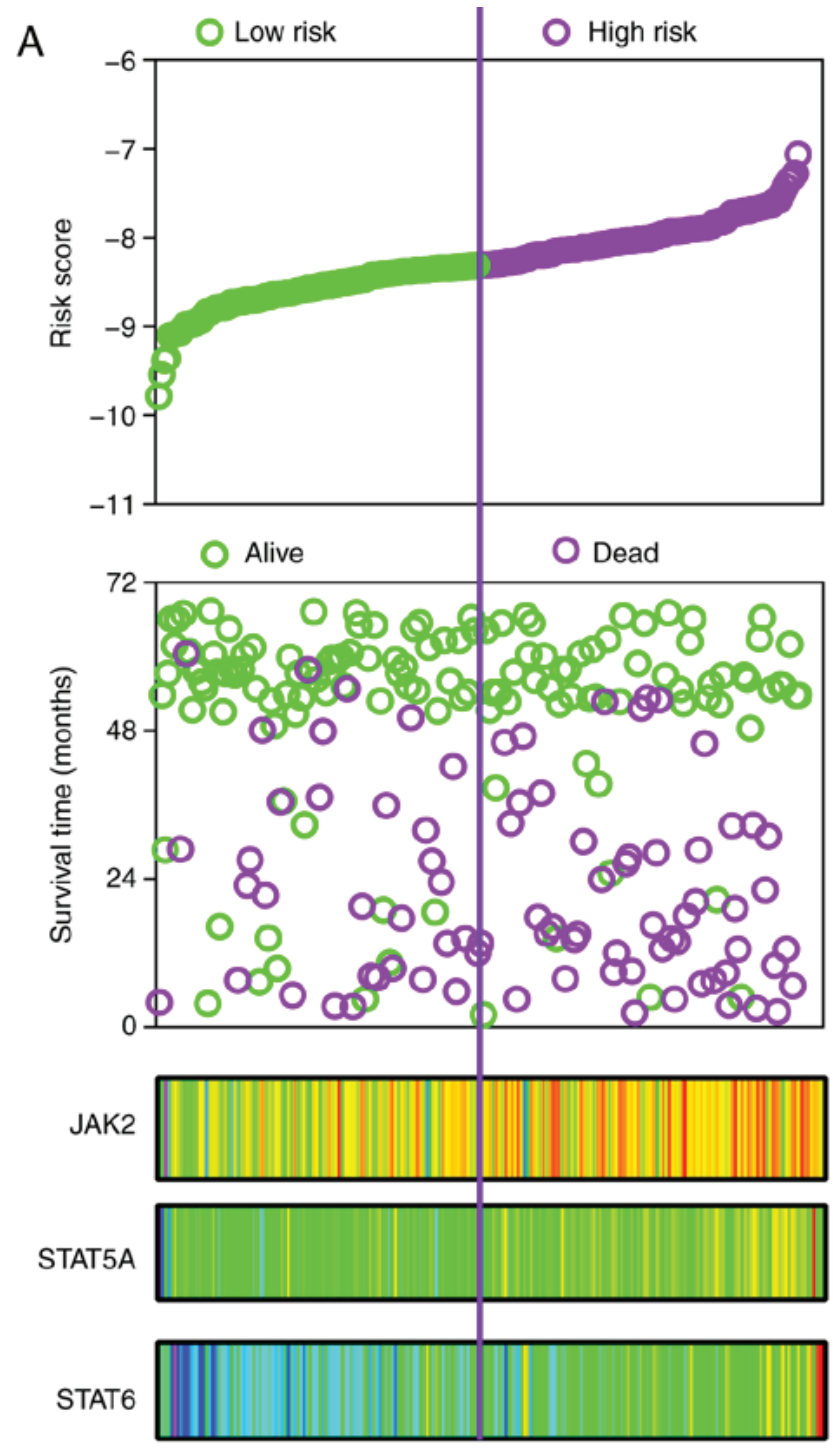

B

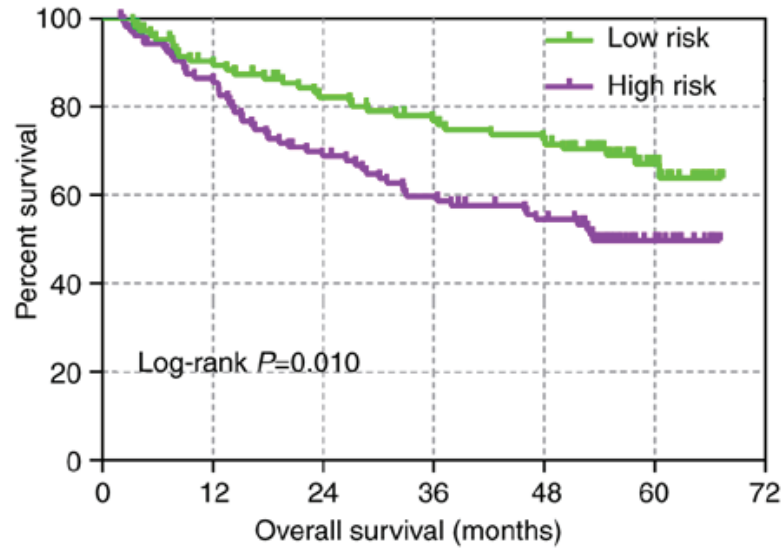

C

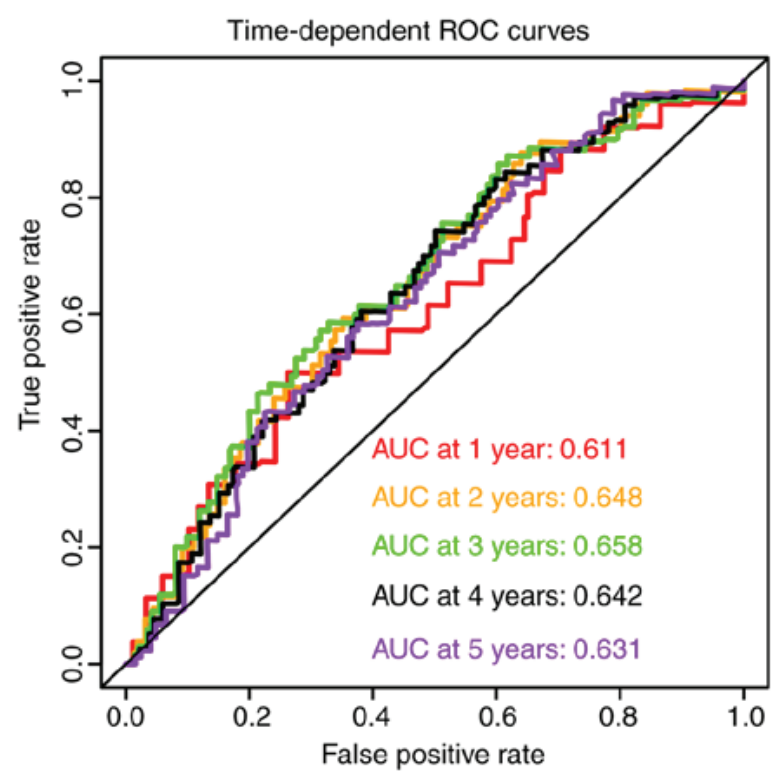

Figure 9. Risk score model, Kaplan-Meier plot, and survival ROC curves in GSE14520 cohort. (A) Risk score model including risk score ranking, survival status, and JAK2, STAT5A and STAT6 heat map. (B) Kaplan-Meier plot of low and high risk score groups. (C) Time-dependent ROC curves at 1,2, 3, 4 and 5 years. JAK, Janus kinase; STAT, signal transducer and activator of transcription; ROC, receiver operating characteristic; AUC, area under the curve.

Peng, Professor Kaiyin Xiao, Professor Ya Guo and Professor Xigang Chen, and Dr Xinping Ye, Dr Zhang Wen and Dr Bin Chen for providing HCC samples.

\section{Funding}

This work was supported in part by the National Nature Science Foundation of China (grant nos. 81560535, 81072321, 30760243, 30460143, 30560133 and 81802874), Natural Science Foundation of Guangxi Province of China (grant nos. 2017JJB140189y and 2018GXNSFAA050119), Key Laboratory of High-Incidence-Tumor Prevention \& Treatment (Guangxi Medical University), Ministry of Education (grant nos. GKE2018-01 and GKE2019-11), 2009 Program for New Century Excellent Talents in University, Guangxi Nature Sciences Foundation (grant no. GuiKeGong 1104003A-7) and Guangxi Health Ministry Medicine Grant (Key-Scientific Research-Grant grant no. Z201018). The present study was also partially supported by Scientific Research Fund of the Health and Family Planning
Commission of Guangxi Zhuang Autonomous Region (grant no. Z2016318), The Basic Ability Improvement Project for Middle-aged and Young Teachers in Colleges and Universities in Guangxi (grant no. 2018KY0110), 2018 Innovation Project of Guangxi Graduate Education (grant no. YCBZ2018036). The present study was also partially supported by Research Institute of Innovative Think-tank in Guangxi Medical University (The gene-environment interaction in hepatocarcinogenesis in Guangxi HCCs and its translational applications in the HCC prevention). The authors also acknowledge the support of the National Key Clinical Specialty Programs (General Surgery \& Oncology) and the Key Laboratory of Early Prevention \& Treatment for Regional High-Incidence-Tumor (Guangxi Medical University), Ministry of Education, China.

\section{Availability of data and materials}

The datasets analyzed during the current study are available from the corresponding author on reasonable request. 
A

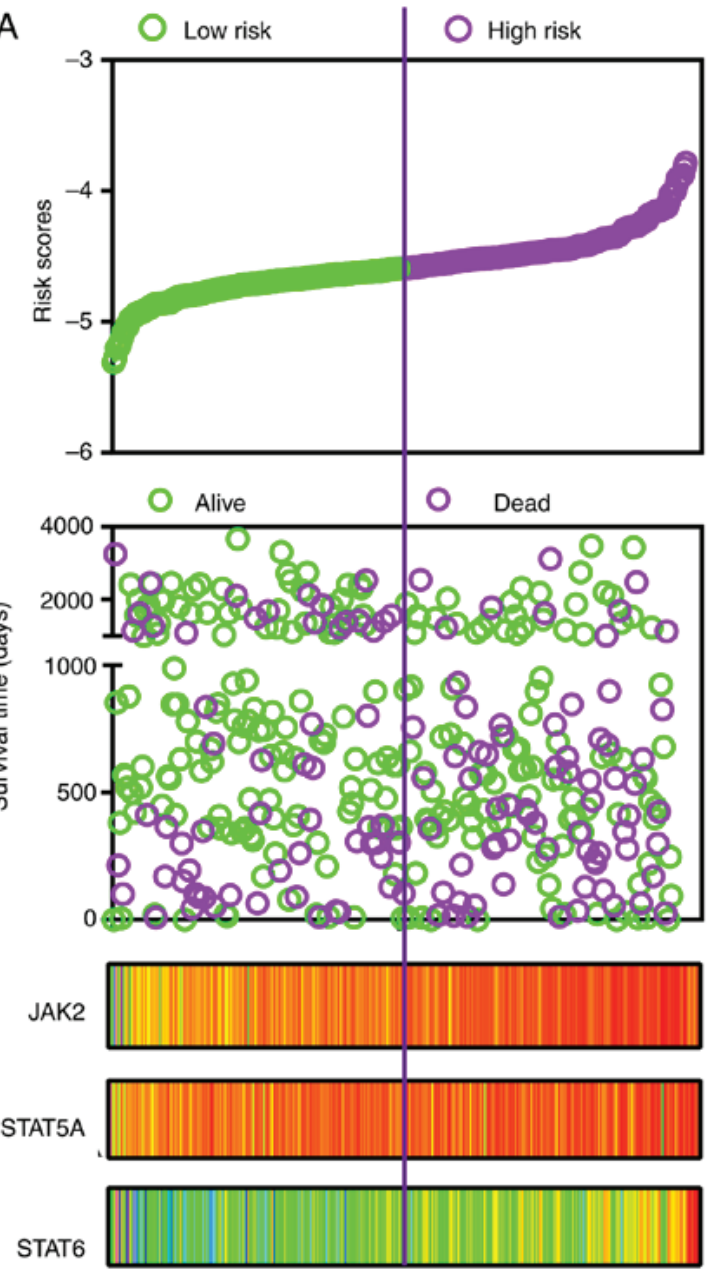

B

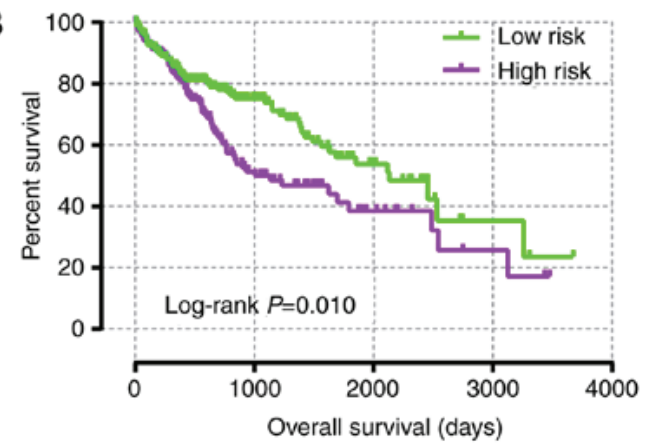

C

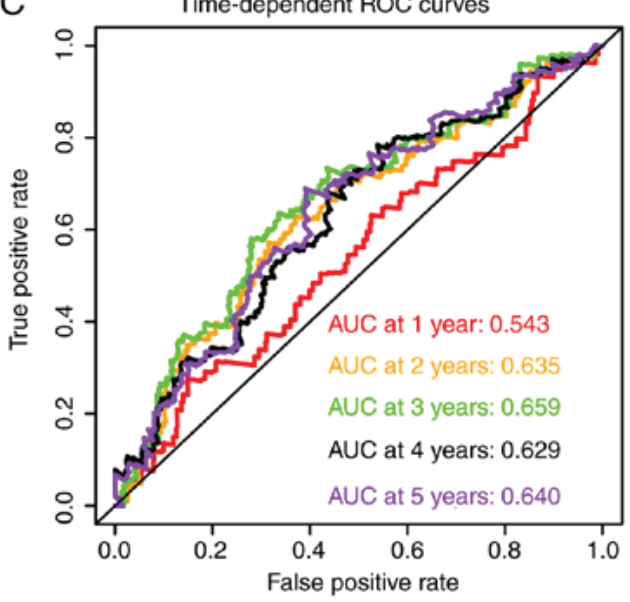

Figure 10. Risk score model, Kaplan-Meier plot, and survival ROC curves in The Cancer Genome Atlas cohort. (A) Risk score model including risk score ranking, survival status, and JAK2, STAT5A and STAT6 heat map. (B) Kaplan-Meier plot of low and high risk score groups. (C) Time-dependent ROC curves at 1, 2, 3, 4 and 5 years. JAK, Janus kinase; STAT, signal transducer and activator of transcription; ROC, receiver operating characteristic; AUC, area under the curve.

A

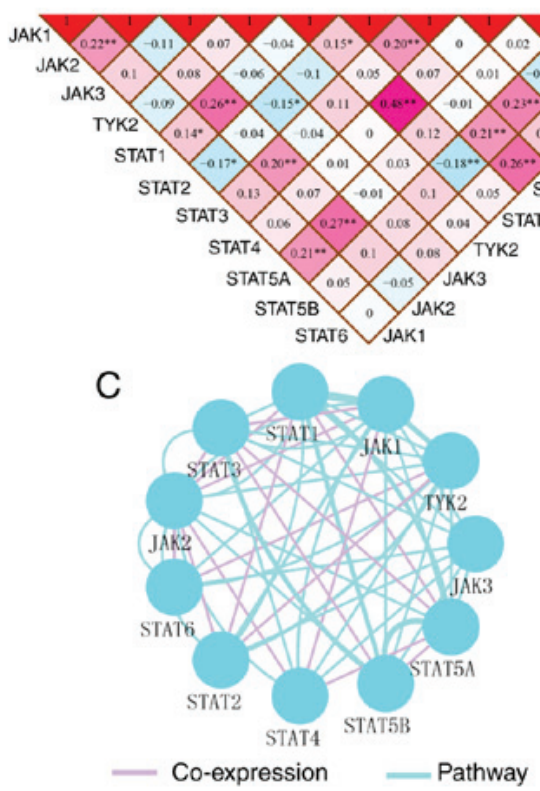

B

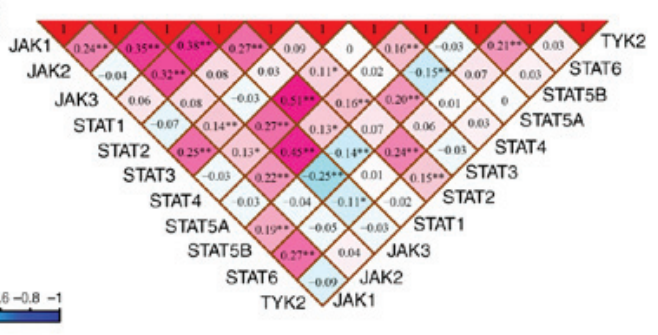

$10.80 .6 \quad 0.4 \quad 0.2 \quad 0-0.2-0.4-0.6-0.8-1$

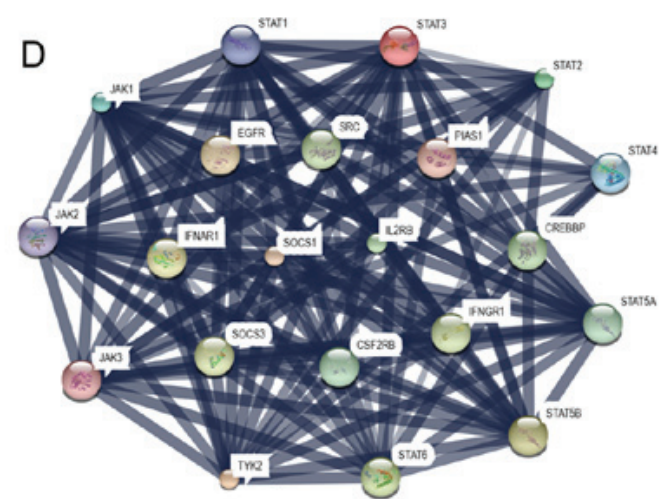

Figure 11. Correlation matrix and interactive networks among JAK/STAT pathway members. Correlation matrix of key genes of JAK/STAT pathway in the (A) GSE14520 and (B) The Cancer Genome Atlas cohorts. (C) Co-expression and pathway interactions of key genes of JAK/STAT pathway. (D) Protein-protein interaction network. ${ }^{*} \mathrm{P} \leq 0.05,{ }^{* *} \mathrm{P} \leq 0.01$. JAK, Janus kinase; TYK2, tyrosine kinase 2; STAT, signal transducer and activator of transcription. 


\section{Author contributions}

XW and TP designed this manuscript; XL, TY, YG, LZ, CH, JH, LY, CY, GZ, WQ, ZL, XZ, JL, QH and TP conducted the study and analyzed the data. XZ wrote the manuscript and TP guided the writing.

\section{Ethics approval and patient consent to participate}

This study was approved by the Ethical Review Committee of the First Affiliated Hospital of Guangxi Medical University [approval no. 2015 (KY-E-032)]. Informed consent was signed by all patients.

\section{Patient consent for publication}

Not applicable.

\section{Competing interests}

The authors declare that they have no competing interests.

\section{References}

1. Forner A, Llovet JM and Bruix J: Hepatocellular carcinoma. Lancet 379: 1245-1255, 2012.

2. Delgado TC, Barbier-Torres L, Zubiete-Franco I, Lopitz-Otsoa F, Varela-Rey M, Fernández-Ramos D and Martínez-Chantar ML: Neddylation, a novel paradigm in liver cancer. Transl Gastroenterol Hepatol 3: 37, 2018.

3. Gerbes A, Zoulim F, Tilg H, Dufour JF, Bruix J, Paradis V, Salem R, Peck-Radosavljevic M, Galle PR, Greten TF, et al: Gut roundtable meeting paper: Selected recent advances in hepatocellular carcinoma. Gut 67: 380-388, 2018.

4. Forner A, Gilabert M, Bruix J and Raoul JL: Treatment of intermediate-stage hepatocellular carcinoma. Nat Rev Clin Oncol 11: 525-535, 2014.

5. Bruix J, Han KH, Gores G, Llovet JM and Mazzaferro V: Liver cancer: Approaching a personalized care. J Hepatol 62 (1 Suppl): S144-S156, 2015.

6. Llovet JM, Real MI, Montaña X, Planas R, Coll S, Aponte J, Ayuso C, Sala M, Muchart J, Solà R, et al: Arterial embolisation or chemoembolisation versus symptomatic treatment in patients with unresectable hepatocellular carcinoma: A randomised controlled trial. Lancet 359: 1734-1739, 2002.

7. Lepage C, Bossard N, Dejardin O, Carmona-Garcia MC, Manfredi S and Faivre J; GRELL EUROCARE-5 Working Group: Trends in net survival from rectal cancer in six European Latin countries: Results from the SUDCAN population-based study. Eur J Cancer Prev 26: S48-S55, 2017.

8. Nault JC, Mallet M, Pilati C, Calderaro J, Bioulac-Sage P, Laurent C, Laurent A, Cherqui D, Balabaud C and Zucman-Rossi J: High frequency of telomerase reverse-transcriptase promoter somatic mutations in hepatocellular carcinoma and preneoplastic lesions. Nat Commun 4: 2218, 2013.

9. Dhanasekaran R, Bandoh S and Roberts LR: Molecular pathogenesis of hepatocellular carcinoma and impact of therapeutic advances. F1000Res 5: F1000, 2016

10. Hussain SP, Schwank J, Staib F, Wang XW and Harris CC: TP53 mutations and hepatocellular carcinoma: Insights into the etiology and pathogenesis of liver cancer. Oncogene 26: 2166-2176, 2007.

11. Bromberg JF: Activation of STAT proteins and growth control. Bioessays 23: 161-169, 2001.

12. Kisseleva T, Bhattacharya S, Braunstein J and Schindler CW: Signaling through the JAK/STAT pathway, recent advances and future challenges. Gene 285: 1-24, 2002.

13. Wormald $\mathrm{S}$ and Hilton DJ: Inhibitors of cytokine signal transduction. J Biol Chem 279: 821-824, 2004.

14. Krebs DL and Hilton DJ: SOCS proteins: Negative regulators of cytokine signaling. Stem Cells 19: 378-387, 2001.

15. Larsen L and Röpke C: Suppressors of cytokine signalling: SOCS. APMIS 110: 833-844, 2002.
16. Poussin K, Pilati C, Couchy G, Calderaro J, Bioulac-Sage P, Bacq Y, Paradis V, Leteurtre E, Sturm N, Ramos J, et al: Biochemical and functional analyses of gp130 mutants unveil JAK1 as a novel therapeutic target in human inflammatory hepatocellular adenoma. Oncoimmunology 2: e27090, 2013.

17. Kang FB, Wang L, Jia HC, Li D, Li HJ, Zhang YG and Sun DX: B7-H3 promotes aggression and invasion of hepatocellular carcinoma by targeting epithelial-to-mesenchymal transition via JAK2/STAT3/Slug signaling pathway. Cancer Cell Int 15: 45, 2015.

18. Ji Y, Wang Z, Li Z, Li K, Le X and Zhang T: Angiotensin II induces angiogenic factors production partly via AT1/JAK2/STAT3/SOCS3 signaling pathway in MHCC97H cells. Cell Physiol Biochem 29: 863-874, 2012.

19. Yoshikawa H, Matsubara K, Qian GS, Jackson P, Groopman JD, Manning JE, Harris CC and Herman JG: SOCS-1, a negative regulator of the JAK/STAT pathway, is silenced by methylation in human hepatocellular carcinoma and shows growth-suppression activity. Nat Genet 28: 29-35, 2001.

20. Livak KJ and Schmittgen TD: Analysis of relative gene expression data using real-time quantitative PCR and the 2(-Delta Delta C(T)) method. Methods 25: 402-408, 2001.

21. Roessler S, Jia HL, Budhu A, Forgues M, Ye QH, Lee JS, Thorgeirsson SS, Sun Z, Tang ZY, Qin LX and Wang XW: A unique metastasis gene signature enables prediction of tumor relapse in early-stage hepatocellular carcinoma patients. Cancer Res 70: 10202-10212, 2010.

22. Roessler S, Long EL, Budhu A, Chen Y, Zhao X, Ji J, Walker R, Jia HL, Ye QH, Qin LX, et al: Integrative genomic identification of genes on 8p associated with hepatocellular carcinoma progression and patient survival. Gastroenterology 142: 957-966.e12, 2012.

23. Tang Z, Li C, Kang B, Gao G, Li C and Zhang Z: GEPIA: A web server for cancer and normal gene expression profiling and interactive analyses. Nucleic Acids Res 45: W98-W102, 2017.

24. Subramanian A, Tamayo P, Mootha VK, Mukherjee S, Ebert BL, Gillette MA, Paulovich A, Pomeroy SL, Golub TR, Lander ES and Mesirov JP: Gene set enrichment analysis: A knowledge-based approach for interpreting genome-wide expression profiles. Proc Natl Acad Sci USA 102: 15545-15550, 2005.

25. Mootha VK, Lindgren CM, Eriksson KF, Subramanian A, Sihag S, Lehar J, Puigserver P, Carlsson E, Ridderstråle M, Laurila E, et al: PGC-1alpha-responsive genes involved in oxidative phosphorylation are coordinately downregulated in human diabetes. Nat Genet 34: 267-273, 2003.

26. Lossos IS, Czerwinski DK, Alizadeh AA, Wechser MA, Tibshirani R, Botstein D and Levy R: Prediction of survival in diffuse large-B-cell lymphoma based on the expression of six genes. N Engl J Med 350: 1828-1837, 2004.

27. Alizadeh AA, Gentles AJ, Alencar AJ, Liu CL, Kohrt HE, Houot R, Goldstein MJ, Zhao S, Natkunam Y, Advani RH, et al: Prediction of survival in diffuse large B-cell lymphoma based on the expression of 2 genes reflecting tumor and microenvironment. Blood 118: 1350-1358, 2011.

28. Wang X, Huang K, Zeng X, Liu Z, Liao X, Yang C, Yu T, Han C, Zhu G, Qin W and Peng T: Diagnostic and prognostic value of mRNA expression of phospholipase $C \beta$ family genes in hepatitis B virusassociated hepatocellular carcinoma. Oncol Rep 41: 2855-2875, 2019.

29. Shannon P, Markiel A, Ozier O, Baliga NS, Wang JT, Ramage D, Amin N, Schwikowski B and Ideker T: Cytoscape: A software environment for integrated models of biomolecular interaction networks. Genome Res 13: 2498-2504, 2003.

30. Montojo J, Zuberi K, Rodriguez H, Kazi F, Wright G, Donaldson SL, Morris Q and Bader GD: GeneMANIA Cytoscape plugin: Fast gene function predictions on the desktop. Bioinformatics 26: 2927-2928, 2010.

31. Maere S, Heymans K and Kuiper M: BiNGO: A Cytoscape plugin to assess overrepresentation of gene ontology categories in biological networks. Bioinformatics 21: 3448-3449, 2005.

32. Szklarczyk D, Morris JH, Cook H, Kuhn M, Wyder S, Simonovic M, Santos A, Doncheva NT, Roth A, Bork P, et al: The STRING database in 2017: Quality-controlled protein-protein association networks, made broadly accessible. Nucleic Acids Res 45: D362-D368, 2017.

33. Cai B, Cai JP, Luo YL, Chen $\mathrm{C}$ and Zhang S: The specific roles of JAK/STAT signaling pathway in sepsis. Inflammation 38: 1599-1608, 2015.

34. Wu HP, Wu CL, Chen CK, Chung K, Tseng JC, Liu YC and Chuang DY: The interleukin-4 expression in patients with severe sepsis. J Crit Care 23: 519-524, 2008. 
35. Steinhauser ML, Hogaboam CM, Lukacs NW, Strieter RM and Kunkel SL: Multiple roles for IL-12 in a model of acute septic peritonitis. J Immunol 162: 5437-5443, 1999.

36. Song GY, Chung CS, Chaudry IH and Ayala A: What is the role of interleukin 10 in polymicrobial sepsis: Anti-inflammatory agent or immunosuppressant? Surgery 126: 378-383, 1999.

37. Nijsten MW, Hack CE, Helle M, ten Duis HJ, Klasen HJ and Aarden LA: Interleukin- 6 and its relation to the humoral immune response and clinical parameters in burned patients. Surgery 109 761-767, 1991.

38. Heinzel FP: The role of IFN-gamma in the pathology of experimental endotoxemia. J Immunol 145: 2920-2924, 1990.

39. Jaime-Figueroa S, De Vicente J, Hermann J, Jahangir A, Jin S, Kuglstatter A,Lynch SM, Menke J,Niu L,Patel V, et al: Discovery of a series of novel 5H-pyrrolo[2,3-b]pyrazine-2-phenyl ethers, as potent JAK3 kinase inhibitors. Bioorg Med Chem Lett 23: 2522-2526, 2013

40. O'Shea JJ, Pesu M, Borie DC and Changelian PS: A new modality for immunosuppression: Targeting the JAK/STAT pathway. Nat Rev Drug Discov 3: 555-564, 2004.

41. Olsen JV, Blagoev B, Gnad F, Macek B, Kumar C, Mortensen P and Mann M: Global, in vivo, and site-specific phosphorylation dynamics in signaling networks. Cell 127: 635-648, 2006.

42. Barahmand-Pour F, Meinke A, Groner B and Decker T: Jak2-Stat5 interactions analyzed in yeast. J Biol Chem 273: 12567-12575, 1998.

43. Gupta S, Yan H, Wong LH, Ralph S, Krolewski J and Schindler C: The SH2 domains of Stat1 and Stat2 mediate multiple interactions in the transduction of IFN-alpha signals. EMBO J 15: 1075-1084, 1996.

44. O'Shea JJ, Holland SM and Staudt LM: JAKs and STATs in immunity, immunodeficiency, and cancer. N Engl J Med 368: 161-170, 2013.

45. O'Shea JJ, Schwartz DM, Villarino AV, Gadina M, Mcinnes IB and Laurence A: The JAK-STAT pathway: Impact on human disease and therapeutic intervention. Annu Rev Med 66: 311-328, 2015.

46. Meier JA and Larner AC: Toward a new STATe: The role of STATs in mitochondrial function. Semin Immunol 26: 20-28, 2014.

47. Leonard WJ and O'Shea JJ: Jaks and STATs: Biological implications. Annu Rev Immunol 16: 293-322, 1998.

48. Bromberg J: Stat proteins and oncogenesis. J Clin Invest 109: 1139-1142, 2002.

49. Xiang Z, Zhao Y, Mitaksov V, Fremont DH, Kasai Y, Molitoris A, Ries RE, Miner TL, McLellan MD, DiPersio JF, et al: Identification of somatic JAK1 mutations in patients with acute myeloid leukemia. Blood 111: 4809-4812, 2008.

50. Luo Q, Wang C, Jin G, Gu D, Wang N, Song J, Jin H, Hu F, Zhang Y, Ge T, et al: LIFR functions as a metastasis suppressor in hepatocellular carcinoma by negatively regulating phosphoinositide 3-kinase/AKT pathway. Carcinogenesis 36: 1201-1212, 2015.

51. Li SJ, Sui MH, Sun ZX and Zhang WW: LncRNA 00152 promotes the development of hepatocellular carcinoma by activating JAK2/STAT3 pathway. Eur Rev Med Pharmacol Sci 23: 1038-1046, 2019

52. Wu Y, Yuan T, Wang WW, Ge PL, Gao ZQ, Zhang G, Tang Z, Dang XW, Zhao YF, Zhang JY and Jiang GZ: Long noncoding RNA HOST2 promotes epithelial-mesenchymal transition, proliferation, invasion and migration of hepatocellular carcinoma cells by activating the JAK2-STAT3 signaling pathway. Cell Physiol Biochem 51: 301-314, 2018.

53. Shu G, Zhao W, Yue L, Su H and Xiang M: Antitumor immunostimulatory activity of polysaccharides from Salvia chinensis Benth. J Ethnopharmacol 168: 237-247, 2015.

54. Sun L, Feng L and Cui J: Increased expression of claudin-17 promotes a malignant phenotype in hepatocyte via Tyk2/Stat3 signaling and is associated with poor prognosis in patients with hepatocellular carcinoma. Diagn Pathol 13: 72, 2018.
55. Chen G, Wang H, Xie S, Ma J and Wang G: STAT1 negatively regulates hepatocellular carcinoma cell proliferation. Oncol Rep 29: 2303-2310, 2013.

56. Liu LY, Huang C, Li ZF, Wang AY, Hu XY, Ni L, Yu L and Song TS: STAT1 and STAT2 participate in growth inhibition of human hepatoma HepG2 cells induced by phosphatidylethanolamine. Nan Fang Yi Ke Da Xue Xue Bao 31: 256-258, 2011 (In Chinese).

57. Zhang L, Xu K, Liu C and Chen J: Meta-analysis reveals an association of signal transducer and activator of transcription-4 polymorphism with hepatocellular carcinoma risk. Hepatol Res 47: 303-311, 2017.

58. Tefferi A: JAK and MPL mutations in myeloid malignancies. Leuk Lymphoma 49: 388-397, 2008.

59. Scott LM: The JAK2 exon 12 mutations: A comprehensive review. Am J Hematol 86: 668-676, 2011.

60. Levine RL, Pardanani A, Tefferi A and Gilliland DG: Role of JAK2 in the pathogenesis and therapy of myeloproliferative disorders. Nat Rev Cancer 7: 673-683, 2007.

61. Sakaguchi H, Okuno Y, Muramatsu H, Yoshida K, Shiraishi Y, Takahashi M, Kon A, Sanada M, Chiba K, Tanaka H, et al: Exome sequencing identifies secondary mutations of SETBP1 and JAK3 in juvenile myelomonocytic leukemia. Nat Genet 45: 937-941, 2013

62. Villarino AV, Kanno Y,Ferdinand JR and O'Shea JJ: Mechanisms of Jak/STAT signaling in immunity and disease. J Immunol 194: 21-27, 2015

63. Manolio TA: Bringing genome-wide association findings into clinical use. Nat Rev Genet 14: 549-558, 2013.

64. O'Shea JJ, Lahesmaa R, Vahedi G, Laurence A and Kanno Y: Genomic views of STAT function in CD4+ T helper cell differentiation. Nat Rev Immunol 11: 239-250, 2011.

65. Vercelli D: Discovering susceptibility genes for asthma and allergy. Nat Rev Immunol 8: 169-182, 2008.

66. Talati PG, Gu L, Ellsworth EM, Girondo MA, Trerotola M, Hoang DT, Leiby B, Dagvadorj A, McCue PA, Lallas CD, et al: Jak2-stat5a/b signaling induces epithelial-to-mesenchymal transition and stem-like cell properties in prostate cancer. Am J Pathol 185: 2505-2522, 2015.

67. Loncle C, Bonjoch L, Folch-Puy E, Lopez-Millan MB, Lac S Molejon MI, Chuluyan E, Cordelier P, Dubus P, Lomberk G, et al: IL-17 functions through the novel REG3 $\beta$-JAK2-STAT3 inflammatory pathway to promote the transition from chronic pancreatitis to pancreatic cancer. Cancer Res 75: 4852-4862, 2015.

68. Calvisi DF, Ladu S, Gorden A, Farina M, Conner EA, Lee JS, Factor VM and Thorgeirsson SS: Ubiquitous activation of ras and Jak/stat pathways in human HCC. Gastroenterology 130: 1117-1128, 2006.

69. Spannbauer MM and Trautwein C: Frequent in-frame somatic deletions activate gp130 in inflammatory hepatocellular tumors. Hepatology 49: 1387-1389, 2009.

70. He G and Karin M: NF-kB and STAT3-key players in liver inflammation and cancer. Cell Res 21: 159-168, 2011.

71. Liao Y, Cai B, Li Y and Wang L: P0360: STAT6 rs3024974 might predict worse prognosis in hepatocellular carcinoma patients. J Hepatol 62 (Suppl 2): S445-S446, 2015.

72. Shi SY, Schroer SA, Luk CT, Kim MJ, Dodington DW, Sivasubramaniyam T, Lin L, Cai EP, Lu SY, Wagner KU, et al: Janus kinase 2 (JAK2) dissociates hepatosteatosis from hepatocellular carcinoma in mice. J Biol Chem 292: 3789-3799, 2017.

This work is licensed under a Creative Commons Attribution-NonCommercial-NoDerivatives 4.0 International (CC BY-NC-ND 4.0) License. 